\title{
WestVirginiaUniversity
}

THE RESEARCH REPOSITORY @ WVU

Graduate Theses, Dissertations, and Problem Reports

2003

\section{Solidification cracking resistance of high strength aluminum alloys}

Rohit K. Paramatmuni

West Virginia University

Follow this and additional works at: https://researchrepository.wvu.edu/etd

\section{Recommended Citation}

Paramatmuni, Rohit K., "Solidification cracking resistance of high strength aluminum alloys" (2003). Graduate Theses, Dissertations, and Problem Reports. 1333.

https://researchrepository.wvu.edu/etd/1333

This Thesis is protected by copyright and/or related rights. It has been brought to you by the The Research Repository @ WVU with permission from the rights-holder(s). You are free to use this Thesis in any way that is permitted by the copyright and related rights legislation that applies to your use. For other uses you must obtain permission from the rights-holder(s) directly, unless additional rights are indicated by a Creative Commons license in the record and/ or on the work itself. This Thesis has been accepted for inclusion in WVU Graduate Theses, Dissertations, and Problem Reports collection by an authorized administrator of The Research Repository @ WVU. For more information, please contact researchrepository@mail.wvu.edu. 


\title{
SOLIDIFICATION CRACKING RESISTANCE OF HIGH STRENGTH ALUMINUM ALLOYS
}

\author{
By \\ Rohit K. Paramatmuni \\ Thesis Submitted to the \\ College of Engineering and Mineral Resources \\ at West Virginia University \\ in partial fulfillment of the requirements \\ for the degree of \\ Master of Science \\ in \\ Mechanical Engineering \\ Keh-Minn Chang, Ph.D; Chair \\ Bruce Kang, Ph.D. \\ Xingbo Liu, Ph.D.
}

Department of Mechanical and Aerospace engineering

Morgantown, West Virginia

2003

Key words: Cracking resistance, Quench cracking tests, Solidification Cracking 


\section{ABSTRACT \\ SOLIDIFICATION CRACKING RESISTANCE OF HIGH STRENGTH \\ ALUMINUM ALLOYS}

Rohit K Paramatmuni

In Direct chill (DC) casting which is used in the manufacture of high strength aluminum ingots evaluation of fracture toughness (cracking resistance) is very much essential to understand the propagation of cracks in ingots.

The objective of this research was to determine the cracking resistance of Al 2024(Al$\mathrm{Cu}-\mathrm{Mg}$ ) and $\mathrm{Al} 3004$ ( Al-Mn-Mg) alloys and to illustrate the relation of cooling rate during solidification and alloy composition on the cracking resistance of these alloys. The specimens were obtained from ALCOA and were first precracked and the cracking resistance was determined by quench cracking tests, which simulated the propagation of cracks under thermal stresses. Tests were performed on specimens obtained from different locations of directionally solidified ingots that exhibited different solidification rates along their length. The solidification rates were similar to the range of real time cast ingots. After the tests microstructures and fractured surfaces of the specimens were examined by optical microscope, SEM and HISCOPE.

The cracking resistance was observed to increase with the solidification rate (which decreases from surface to center in a real time cast DC ingot) for both the alloys and for a given solidification rate the cracking resistance of 3004 was found to be higher than 2024. The above variations were successfully explained based on the microstructural observation and fracture surfaces of the alloys and the effect of alloy composition and solidification rate on cracking resistance was also illustrated. 


\section{ACKNOWLEDGEMENTS}

First of all I would like to thank God for giving me the capability to finish my thesis. I would also like to thank my parents for their constant words of support and encouragement, which helped me to complete my thesis successfully. I would also like to sincerely thank my research advisor and committee chairman, Dr.Keh-Minn Chang for his guidance, encouragement and continuous financial support without whom this work would not have been possible. I would also like to express my appreciation to the thesis committee, Dr.Bruce Kang and Dr.Xingbo Liu for their helpful comments and suggestions regarding this research work. I also extend my profound gratitude to Dr.Gary Morris for his suggestions throughout my course work.

I would also like to mention my special thanks to Dr.Longzhou Ma for his valuable suggestions throughout my work and for his help with the MTS. I would like to appreciate the suggestions and advice provided by Ms.Mao. I would like to thank ALCOA for

providing the specimens to be utilized during the research. I would also like to acknowledge the suggestions and advice provided by Dr. Junpin Lin that was extremely helpful in writing this thesis.

Last but not the least I would like to thank all my relatives and family members who were a great source of inspiration to me. 


\section{TABLE OF CONTENTS}

Title page

Abstract ii

Acknowledgements

Table of contents iv

List of Tables vii

List of Figures viii

Chapter 1 - INTRODUCTION

1.1 Manufacturing process of Aluminum Alloys 1

1.2 Direct Chill Casting Process 1

1.3 Solidification Cracking 3

1.4 Directional Solidification 5

1.5 Research Efforts in the past 5

$\begin{array}{lll}1.6 & \text { Research Objective } & 6\end{array}$

Chapter 2 - LITERATURE REVIEW

$\begin{array}{lll}2.1 & \text { High Strength Aluminum Alloys } & 8\end{array}$

2.2 Cast Structures of Aluminum Alloys 9

2.3 Alloys 2024 and 3004

$\begin{array}{lll}2.4 & \text { Fracture mechanics approach } & 10\end{array}$ 
Chapter 3- EXPERIMENTAL PROCEDURES

$\begin{array}{ll}3.1 \text { Materials } & 12\end{array}$

3.2 Testing system of Quench Cracking 14

$\begin{array}{ll}\text { 3.2.1 Communication in Crack System } & 15\end{array}$

$\begin{array}{ll}\text { 3.2.2 Communication in furnace System } & 17\end{array}$

3.3 Testing Procedure

$\begin{array}{ll}\text { 3.3.1 Precracking of Specimens } & 18\end{array}$

$\begin{array}{ll}\text { 3.3.2 Quench Cracking Test } & 21\end{array}$

3.4 Preparation of Metallographic Specimens 25

$\begin{array}{ll}3.5 & \text { Quantitative Analysis } \\ & 25\end{array}$

$\begin{array}{lll}3.6 & \text { Fractography } & 26\end{array}$

Chapter 4- RESULTS

4.1 Quench Cracking Resistance 27

4.1.1 Alloy $2024 \quad 28$

$\begin{array}{ll}\text { 4.1.2 Alloy } 3004 & 30\end{array}$

4.2 Cast Microstructures 32

4.2.1 Microstructures of 2024 Alloys 33

4.2.2 Microstructures of $\mathbf{3 0 0 4}$ Alloys 38

$\begin{array}{lll}4.3 & \text { Fracture surfaces } & 44\end{array}$

Chapter 5- DISCUSSION

5.1 Comparison of Cracking Resistance 46

$\begin{array}{ll}5.2 \text { Comparison of Microstructure } & 47\end{array}$

$\begin{array}{ll}\text { 5.3 Comparison with Alloys in Literature } & 48\end{array}$ 
Chapter 6- SUMMARY AND FUTURE WORKS

51

REFERENCES

53

APPENDIX

57

Al. PRECRACK CURVES

58

All. QUENCH CRACK CURVES

66

VITA

71 


\section{LIST OF TABLES}

Title:

Table 2.1 Chemical Compositions of Al 2024 and Al $3004 \quad 10$

Table 3.1 Ingot Location Vs Solidification Rate 14

Table 3.2 Quench Cracking Test Procedure 23

Table 3.3 Precrack lengths of Al 2024 and Al 3004

by ASTM E $399 \quad 24$

Table 4.1 Variation of cracking resistance with Solidification Rate for 2024 alloys $\quad 28$

Table 4.2 Variation of cracking resistance with Solidification Rate for 3004 Alloys $\quad 30$

Table 4.3: Variation of Grain size with Solidification Rate for 2024 Alloys $\quad 34$

Table 4.4: Variation of Fraction of Eutectics with solidification Rate for 2024 Alloys

Table 4.5 Variation of Grain size with Solidification Rate for 3004 Alloys

Table 4.6 Variation of Eutectics with Solidification Rates for 3004 Alloys 


\section{LIST OF FIGURES}

Title:

Figure 1.1 Direct Chill Casting 2

Figure 1.2 Different Types of Fracture in Aluminum Ingots 4

$\begin{array}{lll}\text { Figure 3.1 Quench Cracking Specimen } & 13\end{array}$

Figure 3.2 Cooling curves for 7050 Alloy at different Locations 13

Figure 3.3 Communications in Crack System 16

$\begin{array}{lll}\text { Figure 3.4 Communication in Furnace system } & 18\end{array}$

$\begin{array}{llr}\text { Figure 3.5 Precrack curve for Al } 2024 & 19\end{array}$

$\begin{array}{lll}\text { Figure 3.6 Precrack curve of Al } 3004 & 20\end{array}$

Figure 3.7 Precrack curve for Al 3004(second stage) 21

Figure 4.1 Thermal load -Temperature Curve for Al 2024

Figure 4.2 Cracking Resistance Vs Solidification Rate for 2024 Alloys 29

Figure 4.3 Comparison of Fracture Toughness for 2024 Alloys 29

Figure 4.4 Cracking Resistance Vs Solidification rate for 3004 Alloys 31

Figure 4.5 Comparison of fracture toughness for 3004 Alloys 32

Figure 4.6 Microstructures at different locations for 2024 alloys 33

Figure 4.7 Solidification Rate Vs Grain size for 2024 Alloys 35

Figure 4.8 SEM pictures of 2024 Alloys at different locations 36

Figure 4.9 Solidification Rate Vs Area fraction of Eutectics for 2024 Alloy 38

Figure 4.10 Microstructures at different locations for 3004 Alloys $\quad 39$

Figure 4.11 Solidification rate Vs. Grain size for 3004 Alloy 40

Figure 4.12 Microstructure at different locations for 3004 using SEM 42 
Figure 4.13 Solidification Rate Vs Fraction of Eutectics 43

Figure 4.14 Intergranular Fracture of 2024 Alloys 44

Figure 4.15 Transgranular Fracture of 3004 Alloys 44

Figure 5.1 Comparison of Fracture Toughness (2024 Vs 3004) 46

Figure 5.2 Comparison of Grain size (2024 Vs 3004) 47

Figure 5.3 Comparison of Fraction of Eutectics (2024 Vs 3004) 48

Figure 5.4 Comparison of Fracture toughness for different $\begin{array}{ll}\text { high strength Alloys } & 49\end{array}$

Figure A1. Voltage, Crack length Vs No of cycles 58 for Al 2024 (779857-3-1')

Figure A2. Voltage, Crack length Vs No of cycles 58 for Al 2024 (779857-2 -2”)

Figure A3. Voltage, Crack length Vs No of cycles 59 for Al 2024 (779857-4-2’')

Figure A4. Voltage, Crack length Vs No of cycles 59 for Al 2024 (779857-2-8')

Figure A5. Voltage, Crack length Vs No of cycles 60 for Al 2024 (779857-3-8’')

Figure A6. Voltage, Crack length Vs No of cycles $\quad 60$ for Al 2024 (779857-2-4”)

Figure A7. Voltage, Crack length Vs No of cycles 61 for Al 3004 (779858-3-2')

Figure A8. Voltage, Crack length Vs No of cycles $\quad 61$ for Al 2024 (779858-3-2”A) 
Figure A9. Voltage, Crack length Vs No of cycles for Al 3004 (779857-4-4")

Figure A10. Voltage, Crack length Vs No of cycles 62 for Al 3004 (779857-4-4"A)

Figure A11. Voltage, Crack length Vs No of cycles 63 for Al 3004 (779857-2-4")

Figure A12. Voltage, Crack length Vs No of cycles for Al 3004 (779857-2-4"A)

Figure A13. Voltage, Crack length Vs No of cycles 64 for Al 3004 (779857-3-8")

Figure A14. Voltage, Crack length Vs No of cycles for Al 3004 (779857-3-8"A)

Figure A15. Temperature Vs Stress Intensity Factor Al 2024(779857-3-1”) 66

Figure A16. Temperature Vs Stress Intensity Factor Al 2024(779857-4-2”) 66

Figure A17. Temperature Vs Stress Intensity Factor Al 2024(779857-2-4”) 67

Figure A18. Temperature Vs Stress Intensity Factor Al 2024(779857-2-8”) 67

Figure A19. Temperature Vs Stress Intensity Factor Al 2024(779857-3-8”) 68

Figure A20. Temperature Vs Stress Intensity Factor Al 3004(779858-4-2”) 68

Figure A21. Temperature Vs Stress Intensity Factor Al 3004(779858-2-4”) 69 
Figure A22. Temperature Vs Stress Intensity Factor Al 3004(779858-4-4”) 69

Figure A23. Temperature Vs Stress Intensity Factor Al 3004(779858-3-8”) 70 


\section{CHAPTER 1}

\section{INTRODUCTION}

\subsection{Manufacturing Processes of Aluminum Alloys:}

Generally there are two types of alloys, which are mainly used in various engineering applications, castings in shapes or wrought products. The casting of aluminum alloys is nothing but heating the metal in a furnace and transferring it into a mould of required shape. The alloying elements are then added to the metals in the furnace. Some alloys can only be cast to shapes. They cannot be transformed into bars, rods or other forms by hot working because of some constraints in their physical properties.

Casting of ingots is the first stage in the manufacture of wrought alloys. The cast ingots when subjected to a series of mechanical and thermal treatments result in the formation of wrought alloys. A few decades back aluminum ingots were poured into cast iron moulds of specific sizes and shapes, but solidification used to take a lot of time and also it was not possible to produce ingots of large sizes. This was when semi continuous or Direct Chill (DC) casting came into existence [1]. This is the method, which is mostly followed in the production of high strength aluminum alloys, as we can get a very good structure through this process.

\subsection{Direct Chill casting process:}

Direct Chill casting is one of the most important methods in the production of large aluminum ingots. D.C casting is a semi continuos casting process established in 1930's and has been very useful to the aluminum industry since then. Direct Chill casting consists of a mold, which is cooled by water and in which molten metal is poured onto a bottom block. Water sprayer is used to extract heat from the filling liquid metal as the 
bottom block moves down, and molten metal is poured continuously resulting in the formation of the ingot.

The direct chill casting process is shown in the figure 1.1 below and clearly explained in the next paragraph.

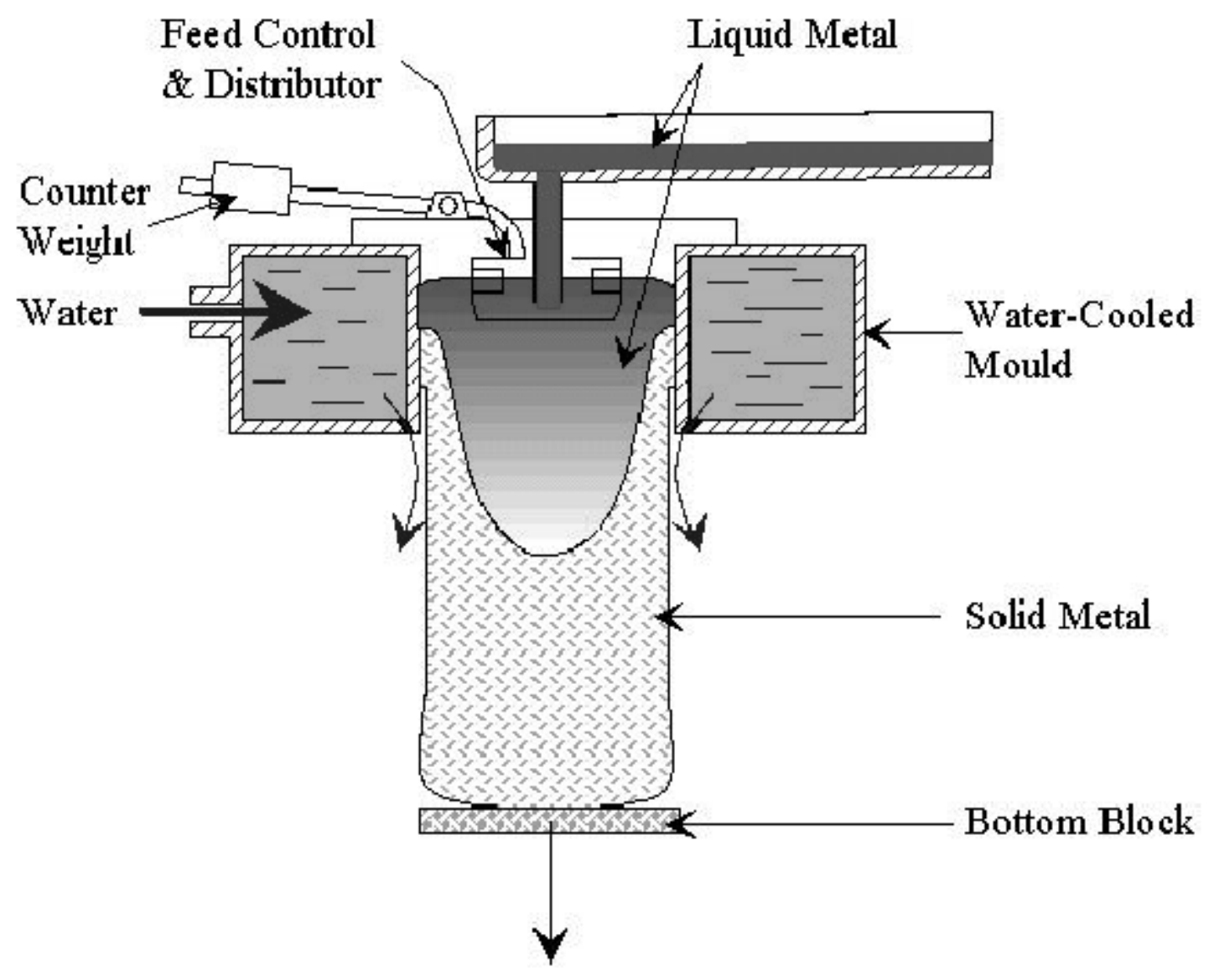

Figure 1.1 Direct Chill Casting [3]

In the beginning stage of the casting process the bottom block is at a height and the molten metal is poured into the mold. After some time when the molten metal reaches some height in the mold the bottom block is moved downward and cooling water is directly sprayed onto the solidified surface of the ingot. The bottom and side surfaces of 
the ingot are solidified first. The bottom block moves downward and the molten metal is continuously poured until the solidification of the entire ingot is achieved [3]. The direct chill casting process consists of three main stages: (1) The transient stage where the temperature field and the shape of the ingot are transient (vary with time) (2) the steady state when the temperature field and shape of the ingot remain almost constant and (3) the final stage during which pouring of molten metal is stopped [3].

\subsection{Solidification Cracking:}

The impinging cooling water, bottom block and the mold rapidly cools the sides and bottom of the ingot. But, the center of the ingot is kept hot because of the molten metal. Because of the uneven cooling rates at different parts of the ingots thermal stresses are generated. Cracks may initiate at the starting phase of casting due to thermal stresses and may propagate eventually. This is called solidification cracking [2]. The casting cracks increase costs of production and also cause a concern for safety hence they should be minimized at all costs.

The formation of ingot crack does not necessarily mean that the ingot fracture must occur. The ingot fracture occurs with the subsequent crack propagation in ingot which is a major concern. The three types of cracks which are very frequent problems in the industry are shown below [3]. Upcenter crack is supposed to be the most frequently occuring type of crack during casting process 


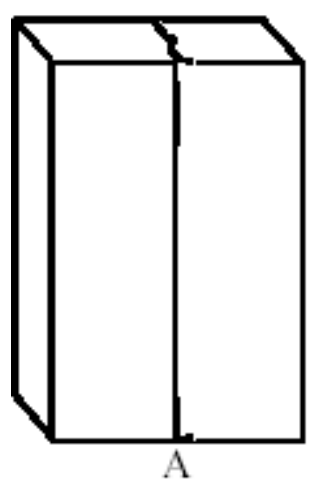

Center Crack

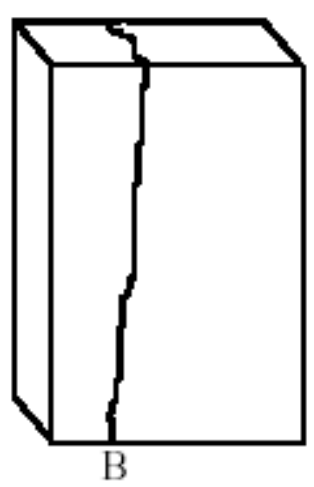

Quarter-point Crack

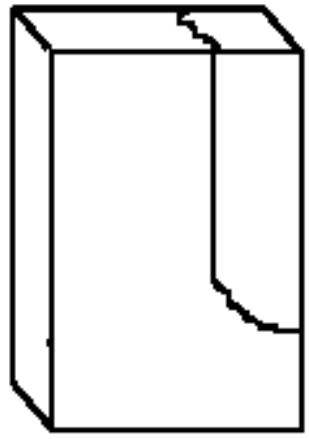

J Crack

Figure 1.2 Different Types of Fracture in Aluminum Ingots [3]

To minimize the thermal stresses a lot of procedures have been adopted. Some of them are: (1) adjusting the casting parameters such as rate of ingot drop, rate of cooling water flow, distribution of cooling water around the mold (2) placing insulation pads between the ingot and the bottom block to reduce the cooling of the ingot bottom through the bottom block. (3) mixing carbon dioxide gas into the cooling water to slow down the heat extraction from the ingot surface (4) using an equipment called top wiper which prevents the cooling water from flowing down the ingot surfaces. [2]

The trial and error processes were found to be expensive. So it becomes very important to understand the stresses responsible for the initiation and propagation of cracks. A lot of research work has been done in the past decade on this area. Also the crack propagates when the driving force is greater than the fracture toughness, Hence the evaluation of fracture toughness (cracking resistance) at different parts of ingot is very much essential to understand the propagation of cracks in ingots. Also a comprehensive study which characterizes the effect of various parameters like alloy composition and solidification rate on the cracking resistance was considered essential. 


\subsection{Directional Solidification:}

When the solidification is made to occur directionally it is called directional solidification. In this type of solidification process the section which is farthest from the liquid metal store solidfies first and the solidifying metal is then fed with the molten metal until the entire section is solidified.

A directional solidification apparatus generally consists of a rectangular mold wrapped in thermally insulating material. The bottom part of the mold which is generally a copper plate is attached beneath a steel frame.Thermocouples are generally located through the mold wall to monitor the cooling at different locations. Molten metal is poured into the mold and copper plate is withdrawn after some time and the bottom of solidifying casting is exposed to the impinging cooling water [19].

\subsection{Research Efforts in the past:}

A lot of work has been done in the past on stresses responsible for ingot cracking. Thermal stress simulation of DC casting has been done by a lot of researchers. Inoue et al. [15] simulated temperature and stress field of a cylindrical ingot in DC casting. A mathematical model ASPEN presented by Fjaer et al. [16] calculated the thermally induced stress and strain during DC casting. A 3D simulation model of steady state and transient process was developed and implemented using ABAQUS by Du et al.[3]. The objective of their investigation was to find out the temperature gradient and thermal stresses responsible for ingot cracking. Most of the work done in the literature considered the material properties as temperature dependent.

Thermomechanical properties of Al 7050 were studied in as cast form and a thermo elastic plastic model was adopted to summarize the ingot strength and deformation 
behavior over a wide range of temperature by Wan [3]. A 2D finite element computational model was used by Wan to predict the stress distribution of ingot during steady state of DC casting. Cooling history of the ingot was also considered an important parameter along with temperature in his model. Briers tried to put forth a relationship between solidification structures and cooling rates for 7050 and 7075 alloys [4].

Recently a lot of research work is being done to simulate the metal casting process.Sen gupta et al. studied the thermomechanical behavior during the transient stage of 5182 aluminum alloy [23]. A constitutive model based on the mechanical behavior within the freezing range was used to estimate the stresses and deformation in the transient stage of Al-Cu-Mg-Zn alloy by Giran et al. [24]. Fjaer et al. conducted the coupled stress, thermal and fluid flow modeling of the transient stage of ingot sheet casting [25].Yang et al. simulated heat transfer,fluid flow,solid transport and microstructure evaluation during soldification scale in a laboratory scale DC simulator [26]. A method for numerical simulation of thermal stresses during the casting of aluminum slabs was put forth out by Barral et al.[27]

\subsection{Research Objective:}

The objective of this research was to determine the cracking resistance (fracture toughness) of cast $\mathrm{Al} 2024$ and Al 3004 alloys and to illustrate the relation of cooling rate during solidification and alloy composition on quench cracking resistance of high strength Al 2024(Al-Cu-mg) and Al 3004 (Al-Mn-Mg) alloys. The alloys used were high strength aluminum alloys 2024(Al-Cu-Mg) and high ductility 3004 (Al-Mn-Mg) which were very much different in their composition. 
Quench cracking tests developed by Prof.Keh Minn Chang at WVU which potray the propagation of cracks under thermal stresses were performed on specimens cut from different locations (having different solidification rates) of directionally solidified (DS) ingots to determine the cracking resistance. All the specimens were first precracked before quench cracking tests. Quench cracking occurs with a rapid failure when driving force (caused by the thermal stresses which are produced because of cooling from elevated temperature) exceeds the fracture toughness. All the tests were performed on a hydraulic Material Test System (MTS) 810. Results of the tests were then analyzed and presented and sucessfully explained taking into account the microstructure, grain size . and fracture surfaces. In this research also the dependancy of cracking resistance on the cooling history taking alloy composition into account is emphasized. 


\section{CHAPTER 2}

\section{LITERATURE REVIEW}

\subsection{High strength Aluminum alloys:}

Many aluminum alloys have been developed in the past few decades and many more with specific required properties have to be developed. Hence alloy development with necessary microstructure and properties is very essential and useful.

High strength aluminum alloy 2024 was introduced in 1930's. This alloy is a natural aging one used extensively in the aircraft applications. It is available in all wrought product forms like drawn wire, rod and bar. The major elements in alloy 2024 are aluminum, copper and magnesium and its typical applications include aircraft structures, rivets, hardware, truck wheels, screw machine products and other miscellaneous structural applications.

The oldest commercial aluminum-manganese-magnesium alloy is 3004 . It was introduced in 1929. Its applications include chemical handling and storage equipment, sheet metal work, builder's hardware, incandescent and fluorescent lamp bases and similar applications requiring good formability and high strength. Alloy 3004 is available in the form of sheet, plates, and tubes [5].

The other high strength aluminum alloys on which research was done earlier and with which we are going to compare our results are 7050 and 7075 Alloys. These are extensively used for aircraft applications. 


\subsection{Cast structures of Aluminum alloys:}

The as-cast structure is very different when compared with wrought product. The as-cast structure of aluminum alloy generally consists of an array of grains having a dendritic structure. Primary aluminum surrounded by heavily cored solid solution regions essentially form the as cast structure. A wide range of soluble and insoluble phases is usually present along the dendrite boundaries. Matrix in most of the commercial aluminum alloys is the solid solution dendrites of primary aluminum. The interdendritic spaces are filled by the binary, ternary and more complex eutectics.

According to Chang et al. [7] the cooling curves during DC casting vary from location to location. From the cooling curves of both the transient stage and steady stage, in D.C casting faster solidification rates was observed near the surface and corner of ingots, while slow solidification rate was observed near the center.

According to Belov et al. [10] for high strength castable aluminum alloys there is generally a capacity for intergrain fracture but for a castable alloy (Al-6\%Zn-1.6\%Mg$1 \% \mathrm{Cu}$ ) with the introduction of $4 \% \mathrm{Ni}$ in the composition the fracture surface is changed from inter grain to intra grain. Belov observed an increase in volume fraction of intragrain particles (eutectic phases), which causes the transition from intergranular to intragranular fracture resulting in an increase in fracture toughness.

\subsection{Alloys 2024 and 3004:}

The chemical composition of Al 2024 and Al 3004 obtained from the Metals Hand book [6] are given below: 
Table 2.1 Chemical Compositions of Al 2024 and Al 3004

\begin{tabular}{|c|c|c|c|c|c|c|c|}
\hline Alloy type & $\mathrm{Cu}$ & $\mathrm{Si}$ & $\mathrm{Fe}$ & $\mathrm{Mn}$ & $\mathrm{Mg}$ & $\mathrm{Zn}$ & $\mathrm{Al}$ \\
\hline Al 2024 & $3.8-4.9$ & 0.05 & 0.5 & $0.3-0.9$ & $1.2-1.8$ & 0.25 & Balance \\
\hline Al 3004 & 0.25 & 0.3 & 0.7 & $1-1.5$ & $0.8-1.3$ & 0.25 & Balance \\
\hline
\end{tabular}

The major alloying elements in 2024 are Al-Cu-Mg and in 3004 is Al-Mn-Mg as seen from above.

According to Sun et al. [8] intermetallic particles having skeletal and plate like shape play an important role in deciding the properties of Al-Mn-Mg Alloys (Al 3004). It was observed that most of the intermetallic particles were $\beta-\mathrm{Al} \mathrm{I}_{6}(\mathrm{Fe}, \mathrm{Mn})_{3}$ and a few of them with fine black skeleton were found to be $\mathrm{Mg}_{2} \mathrm{Si}$. It was very difficult to distinguish between $\alpha$ and $\beta$ particles during metallographic observation.

According to Xie et al. [9] the microstructure of Al-Cu-Mg Alloys (2024) consists of the $\alpha-\mathrm{Al}$ and $v\left(\mathrm{Al}_{2} \mathrm{Cu}\right)$ phases and the ternary eutectic which consists of $\alpha, v$ and $\mathrm{S}$ $\left(\mathrm{Al}_{2} \mathrm{MgCu}\right)$. The dendrite arms were observed to be separated by $v$ and ternary eutectic.

\subsection{Fracture mechanics Approach:}

Design of crack tolerant structures recognize fracture mechanics approach as an important tool. High local stresses and strains are always present near the locations of stress concentrators like cracks. Hence to evaluate the critical driving force that cause cracks to propagate fracture mechanics approach can be used. A parameter called the 
stress intensity factor is defined which takes the effects of loading, crack size and geometry into account. The stress intensity factor is given by

$$
\mathrm{K}=C \sigma \sqrt{\Pi a} \ldots \ldots \ldots \ldots \ldots \ldots \ldots \ldots \text { Eqn }
$$

in which $\mathrm{C}$ is the geometric constant, is the stress and a is the crack length.

If the stress concentration exceeds a particular value then the material undergoes a catastrophic failure, that is if $\mathrm{K}$ reaches $K_{Q}$, which is the fracture toughness or the quench cracking resistance of the material then the crack rapidly propagates to failure. 


\section{CHAPTER 3}

\section{EXPERIMENTAL PROCEDURES}

\subsection{Materials:}

The specimens used in this study were manufactured and supplied by ALCOA (Aluminum Company of America). The alloys used in this research were alloys Al 2024 and 3004. The specimens were cut at different locations (1", 2", 4", 8") or $(25.4 \mathrm{~mm}$, $50.8 \mathrm{~mm}, 101.6 \mathrm{~mm}, 203.2 \mathrm{~mm}$ ) respectively from the bottom of directionally solidified ingots 2024 and 3004. The different positions had different solidification rates. Specimens cut from the specific locations had the cooling rates during solidification that were similar to the range of real time DC casting.

The specimens used in these experiments were of dog bone shape as shown in the figure 3.1. Drilling machine was used to drill holes on both sides of the notch and $k$ type thermocouples were inserted. Figure 3.1 represents the original drawing of the quench crack specimen (Note that all the dimensions are in inches).

The cooling curves for specimens at different locations were obtained from ALCOA for 7050 alloys and the solidification rate during cooling was calculated. The same solidification rate was assumed for specimens at same locations for both 2024 and 3004 alloys. The cooling curves for different locations of ingot are shown in figure 3.2 below for 7050 and the solidification rate was calculated and tabulated as shown in the table

\section{1}




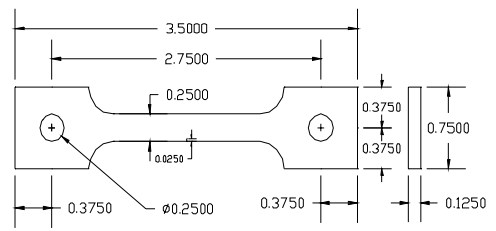

QUENCH CRACK SPECIMEN

Figure 3.1 Quench crack specimen

7050 D. S. Casting
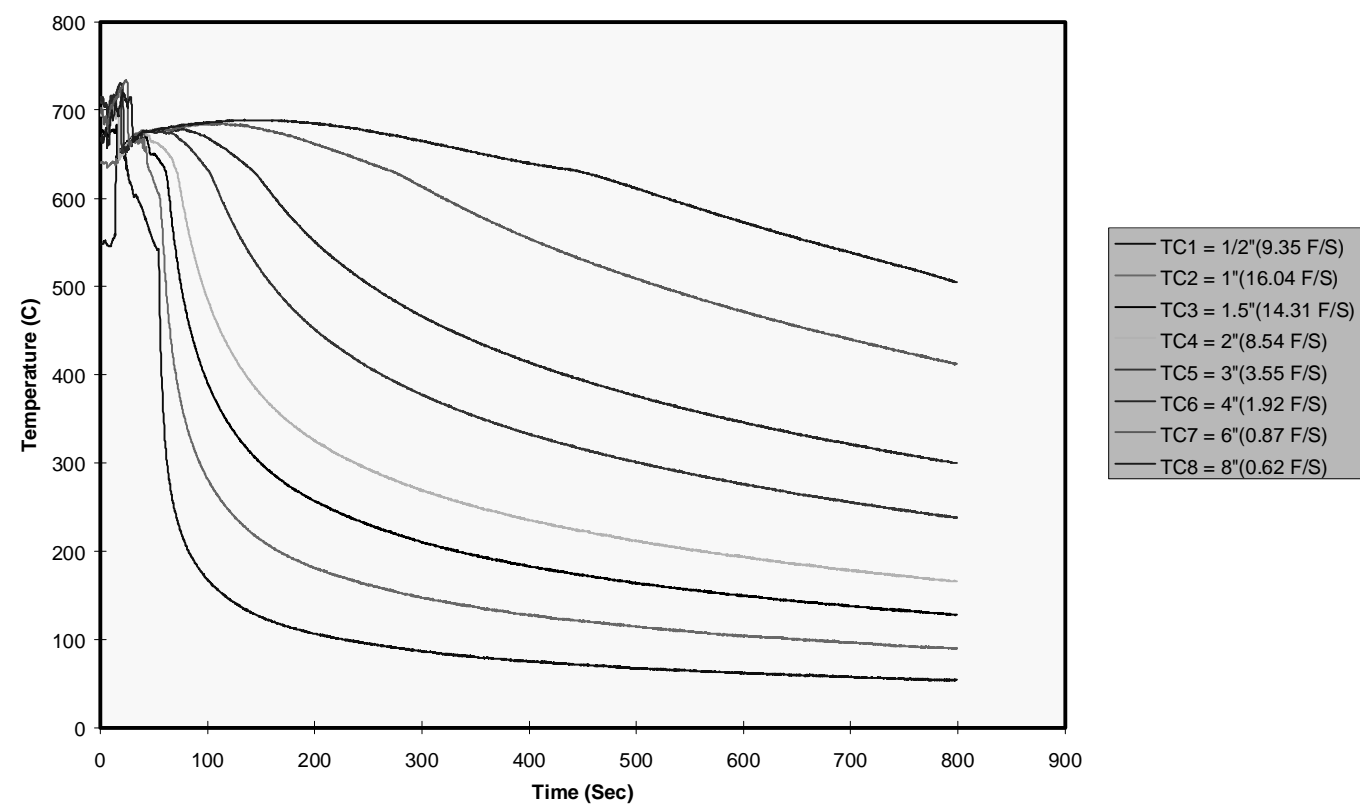

Figure 3.2 Cooling curves for 7050 Alloy at different Locations (Courtesy ALCOA) 
The table 3.1 shows the Ingot location Vs Solidification Rate

Table 3.1: Ingot Location Vs Solidification Rate

\begin{tabular}{|c|c|}
\hline $\begin{array}{c}\text { DISTANCE FROM BOTTOM } \\
\text { OF D.S ALLOY }(\mathrm{mm})\end{array}$ & SOLIDIFICATION \\
& RATE $\left({ }^{\circ} \mathrm{C} / \mathrm{S}\right)$ \\
\hline 25.4 & 8.6 \\
\hline 50.8 & 4.44 \\
\hline 101.6 & 0.77 \\
\hline 203.2 & 0.048 \\
\hline
\end{tabular}

\subsection{Testing system of Quench Cracking:}

All the experiments were carried out on a Material test system (MTS) with a fully computer controlled data acquisition system. The components used in this system were as follows:

1) MTS 318.10 B test frame 2) MTS 458.20 micro console 3) 458.11 DC force controller 4) 458.13 AC displacement controller 5) 458.91 micro profiler 6) Two zone load test heater 7) SCR power controller (Model 5620) 8) Barber coleman 560 series temperature controller 9) HP 6033 A power supply 10) HP 34401A multimeter 11) Pentium personal computer 12) AT-MIO-16E-10 and AT-GPIB/TNT interfaces and 13) Pentium personal computer.

Prof. Keh-Minn Chang at WVU developed the software. The language used in this program was Lab view Software version 3.1.1. It has a lot of testing capabilities including tension, compression, fracture toughness, fatigue crack growth, quench cracking and 
heat treatment. The tension, compression, fatigue crack growth and fracture toughness tests had the option to be conducted either at room temperature or high temperature.

Fatigue crack growth and quench crack tests were used to obtain results in this thesis. In the fatigue crack growth tests either static or dynamic load could be selected. The dynamic load had the option to be either triangle or trapezoid wave. The quenchcracking test also had the option to be conducted at natural cooling rate or specified cooling rate. As soon as a specific test condition was selected on the software a screen popped up which allowed the user to specify various parameters like specimen dimensions, loading conditions and testing temperature etc.

\subsubsection{Communication in Crack monitor system:}

The crack monitor system components were HP 6033A power supply, HP 34401 Multimeter and computer with AT-GPIB/TNT interface as shown in the figure 3.2. HP $6033 \mathrm{~A}$ power supply was used to provide constant current to the specimen. As the crack length of the specimen increased, the resistance of the specimen increased resulting in an increase of potential drop across the crack. The change in the voltage was detected by the multimeter, which would send the message to the computer through ATGPIB/TNT. The computer then used to calculate the new length based on Johnson's equation.

$$
\frac{V}{V_{o}}=\frac{\cosh ^{-1}\left(\cosh \left(\frac{\Pi Y}{2 W}\right) / \cos \left(\frac{\prod a}{2 W}\right)\right)}{\cosh \left(\cosh \left(\frac{\Pi Y}{2 W}\right) / \cos \left(\frac{\prod a_{o}}{2 W}\right)\right)} \ldots \ldots \ldots . . . \operatorname{Eqn}(3.1)
$$


Where $\mathrm{Y}$ is half the distance between notches; $\mathrm{W}$ is the width of the specimen; $\mathrm{V}_{0}$ is the initial electric potential for initial notch depth $\mathrm{a}_{0} ; \mathrm{V}$ is the electric potential for crack length a. The Johnson's equation is valid only for single edge notch (SEN) type of specimens. There are other formulae for other type of specimens. Hence using a DC potential drop technique the crack propagation was continuously monitored. The main purpose of a crack monitor system was to control the stress intensity level $\mathrm{K}$.

Figure 3.3 below shows the flow chart of a crack monitor system

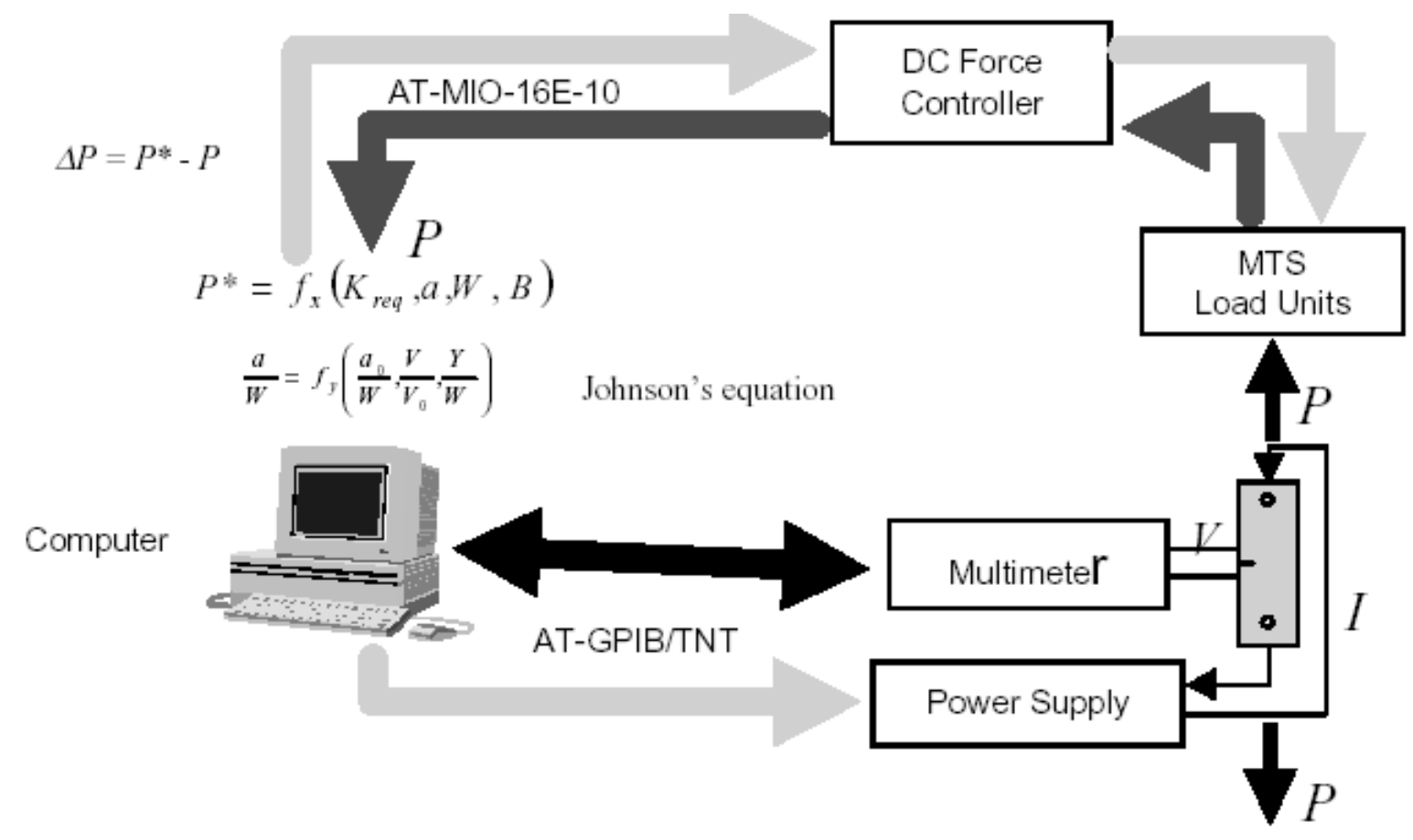

Figure 3.3 Communications in Crack System [28]

After crack propagates Tada's Empirical equation [18] was used to evaluate the new load level based on the requested $\mathrm{K}$ level and new crack length. 


$$
K=\frac{P}{B \sqrt{W}} \frac{\sqrt{2 \tan \left(\frac{\prod a}{2 w}\right)}}{\cos \left(\frac{\prod a}{2 w}\right)}\left[0.752+2.02\left(\frac{a}{w}\right)+0.37\left(1-\sin \frac{\prod a}{2 w}\right)\right]^{3} \ldots \ldots . . \operatorname{Eqn}(3.2)
$$

Where $P$ is the applied load, $B$ is the thickness and $\theta=\pi a / 2 w$. After comparing the load with the load level measured from the load cell, computer adjusted the load applied to the specimen by sending out proper signal to DC force controller through AT-MIO-16 E10 interface.

\subsubsection{Communication in furnace system:}

Furnace system consisted of two zone load test heaters units, two power controller units, two temperature controller units, one temperature transmitter unit, and a computer with AT-MIO-16E-10 interface. Specimen was heated by using two zone load test heater units. The temperature of each side was measured by a $K$ type thermocouple and the signal was sent to both the temperature controller and temperature transmitter. The temperature controller then used to send proper control signal $(4-20 \mathrm{~mA})$ to the power controller. The energy output to the load test heater was then adjusted.

Computer used to set the desired temperature in the temperature controller using $0-4$ DC signal which was generated by one of the analog output channels in AT-MIO-16E-10 Interface board. In a similar way temperature controller and temperature transmitter converted the temperature-measured signal into 0-4 DC signal and used to send it to one of analog input channels in AT-MIO-16E-10 interface board. After A/D conversion in AT-MIO-16E-10 Interface board, the digital data was retrieved by the computer and 
converted back to corresponding temperature values. Figure 3.4 shows the flow chart of a furnace system.

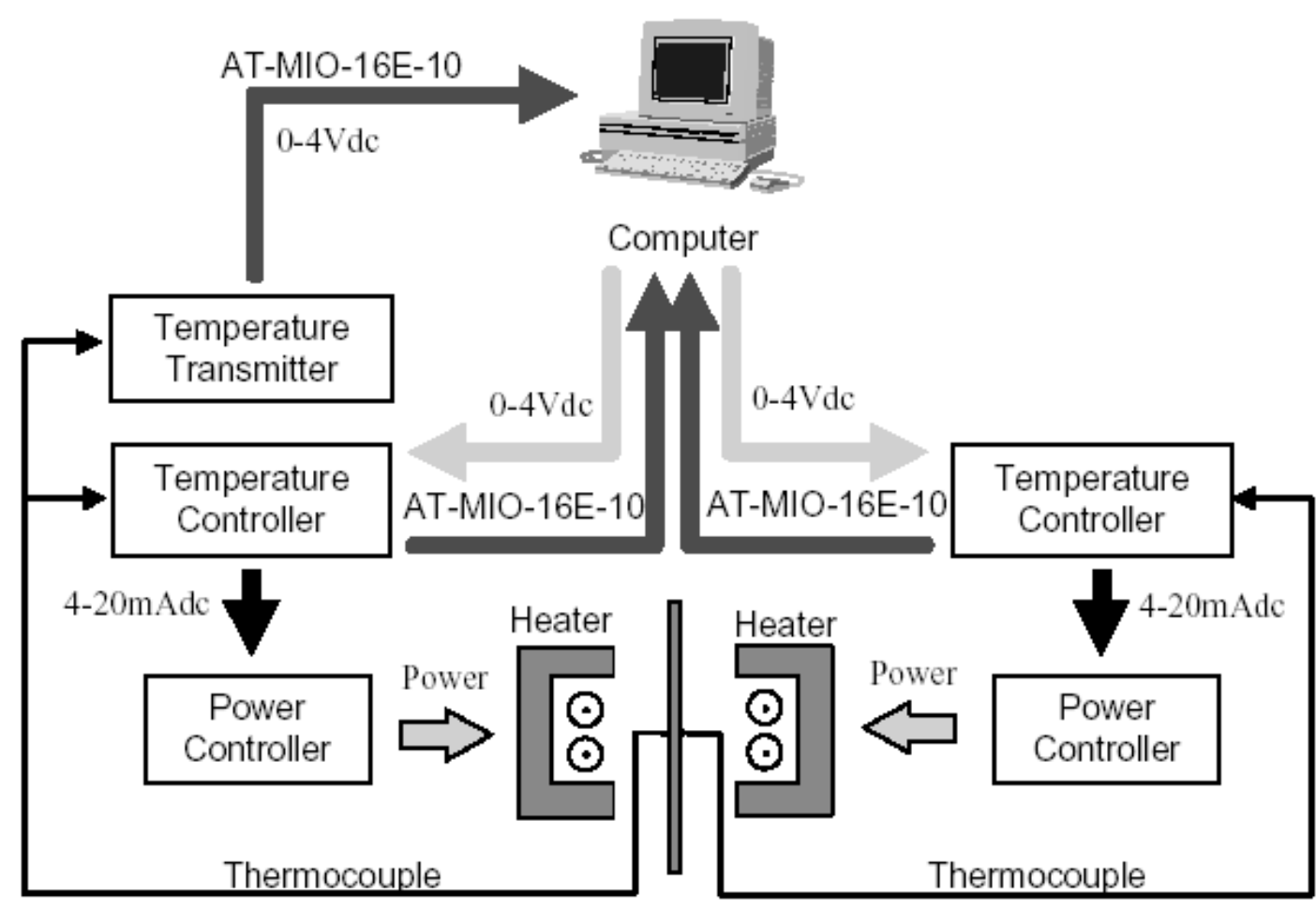

Figure 3.4 Communication in Furnace systems [28]

This furnace system had the capability of fast heat and cooling which is very important for measuring quench-cracking properties of materials. Hence to catch up with the cooling speed a fast temperature device (Temperature transmitter) was used.

\subsection{Testing procedure:}

\subsubsection{Precracking of fracture specimens:}

Precracking is one of the most important steps in the determination of quench cracking resistance. As there is a large chance of the specimen breaking during precracking (especially for as cast alloys), utmost care was taken during precracking. Random value 
of stress intensity factor $(\mathrm{K})$ was selected at first and it was increased slowly to get the desired crack length. All the samples were precracked at the room temperature using an 810 Material test system (MTS) 810 . A range cartridge of \pm 0.5 inches $(12.7 \mathrm{~mm})$ and a load cartridge of \pm 2 kips $(8.89 \mathrm{KN})$ was used. A HP 34401 multimeter monitored the crack voltage and a constant current of 10 amps was used. A dynamic triangle waveform was chosen and precracking was done with a constant stress concentration factor $(\mathrm{K})$ ranging from 5.274 to $6.043 \mathrm{Mpa} \sqrt{m}$.

The software developed by Prof.Keh Minn Chang was used for testing. A triangular waveform with frequency of $10 \mathrm{~Hz}$ or cycles per second was also used. The data was saved for every 100 cycles. Most of the specimens were precracked between 35 to $50 \%$ of the width of the specimen. After precracking, the length of the precrack was measured with calipers and the actual length of the precrack was noted which are given in the Appendix.



Figure 3.5 Precrack curves for Al 2024 
As shown in the figure 3.5 the load ratio between the maximum and minimum stress used for fatigue precracking of 2024 specimens was 0.2 . Stress intensity factor was 5.6 Mpa $\sqrt{m}$, thickness of the specimen was $3.175 \mathrm{~mm}$ and the width of the specimen was 6.223 mm. Graphs were plotted between crack length, voltage vs. no of cycles. It was observed that both the voltage and crack length increased linearly with the increase in no of cycles and the value of the stress intensity factor varied with the specimens.



Figure 3.6 Precrack curve of Al 3004(first stage)

As shown in the figure 3.6 above the load ratio used for precracking of 3004 alloys was 0.1. The width of the specimen was $6.223 \mathrm{~mm}$ and the thickness of the specimen was $3.175 \mathrm{~mm}$. Precracking of 3004 alloys was generally done in two stages. In the first stage a random value (5.823 $\mathrm{Mpa} \sqrt{m}$ in the above case) of stress intensity factor was selected. It was observed that after reaching certain crack length (which was not the required crack length) the crack stopped to propagate, so the stress intensity factor was increased in the second stage and the change in crack length with the number of cycles was observed. 


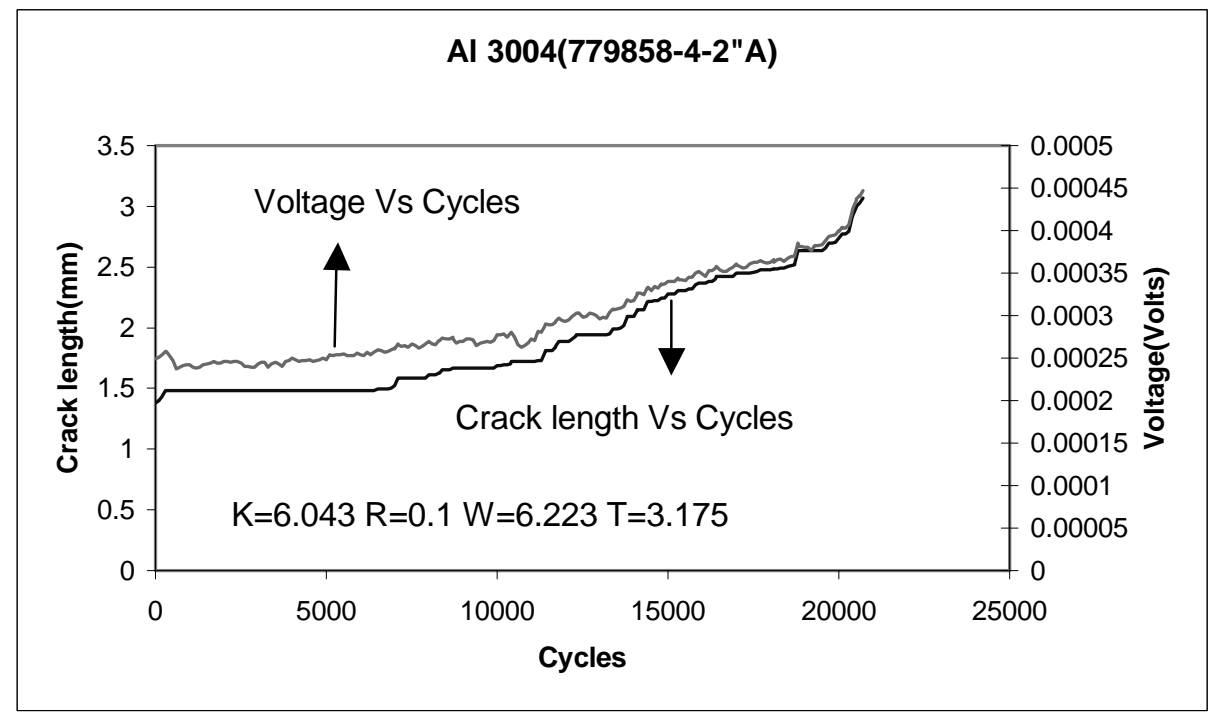

Figure 3.7 Precrack curves for Al 3004(second stage)

As seen from the figure 3.7 both the voltage and crack length increased linearly with the no of cycles when a higher value of stress intensity factor was used $(K=6.043$ $\operatorname{Mpa} \sqrt{m}$ ). By increasing the value of the stress intensity factor the specimens were precracked to obtain the desired crack length.

\subsubsection{Quench cracking Test:}

Quench cracking test used to determine the cracking resistance of materials under thermal loading was performed after precracking. In the quench-cracking test generally the specimen was first heated to the solution temperature and then quenched to room temperature using natural cooling or controlled cooling. In our case natural cooling was used. The specimen was held tightly between the grips and the thermal load was 
introduced. The maximum load was then used to calculate cracking resistance using Tada's equation [18].

Thermocouple was first wound on the opposite sides at the surface of the specimens. A displacement cartridge of \pm 0.5 inches $(12.7 \mathrm{~mm})$ and a force cartridge of \pm 2 kips $(8.89 \mathrm{KN})$ was used for the quench crack test. Water flowing through the copper tubes cooled the grips, which were inturn used to hold the specimens. High power quartz light furnaces were mounted to the MTS machine. A three phase insulated transformer was used to power the furnaces and controllers. Barber-Coleman 560 displays showed the temperature of the specimen surface.

The quench-cracking test was performed by selecting the natural cooling. The tests were conducted on an MTS by setting the controls to load control. Initially the load was set to zero before the testing began. A slight load was applied just before cooling to prevent any loss of time for the specimen to come back into contact with the pins that were used to hold it in place.

The specimen temperature and load for each specimen were recorded and the results stored for further analysis. The program stopped each time with the breaking of the specimen.

The following are the steps required to do the a quench cracking test: 
Table 3.2 Quench Cracking Test Procedure:

\begin{tabular}{|l|l|}
\hline STEPS & \\
\hline Step1 & The specimen is first installed on the MTS. \\
\hline Step 2 & Furnace and cooling devices are turned on. \\
\hline Step 3 & The MTS is set to load control and load is kept at almost zero. \\
\hline Step 4 & The primary ramp rate was set up at $176.6^{\circ} \mathrm{C} /$ Min up to $371.1^{\circ} \mathrm{C}$. \\
\hline Step 5 & $\begin{array}{l}\text { When the temperature is stabilized at } 371.1^{\circ} \mathrm{C}, \text { the second ramp rate was set } \\
\text { up at } 23.8^{\circ} \mathrm{C} \text { until the temperature reached } 454.4^{\circ} \mathrm{C}\end{array}$ \\
\hline Step 6 & The specimen is held at $454.4^{\circ} \mathrm{C}$ for 2 minutes. \\
\hline Step 7 & Then the machine is shifted to displacement control and the cooling process is \\
started.
\end{tabular}

After the quench cracking tests were completed, accurate crack lengths of the broken specimens were measured using hi scope. The precrack lengths were measured using ASTM E 399 standards. This was nothing but taking five measurements of the precrack at standard locations and then calculating the final length based on these five lengths. Measurements were taken from a1 (bottom edge), a5 (top edge), a3 (center), a2 and a4 (equal distances from a3) to the crack length and the effective precrack length was calculated. The precrack measurements using HI SCOPE are given in table 3.5. 
Table 3.3: Precrack lengths of Al 2024 and Al 3004 by ASTM E 399

\begin{tabular}{|l|l|l|l|l|l|l|}
\hline TYPE & a1 $(\mathrm{mm})$ & a2 $(\mathrm{mm})$ & a3 $(\mathrm{mm})$ & a4 $(\mathrm{mm})$ & a5 $(\mathrm{mm})$ & a6 $(\mathrm{mm})$ \\
\hline $857-3-1 "$ & 2.057 & 2.032 & 2.209 & 2.387 & 2.362 & 2.209 \\
\hline $857-4-2 "$ & 2.057 & 2.286 & 2.032 & 1.752 & 2.286 & 2.057 \\
\hline $857-2-4 "$ & 2.171 & 2.235 & 2.286 & 2.057 & 2.00 & 2.159 \\
\hline $857-2-8 ”$ & 1.981 & 1.955 & 1.803 & 1.955 & 1.930 & 1.905 \\
\hline $857-3-8 "$ & 1.803 & 1.930 & 1.955 & 2.000 & 1.930 & 1.930 \\
\hline $858-4-2 "$ & 4.241 & 4.445 & 4.394 & 4.292 & 4.013 & 4.292 \\
\hline $858-2-4 "$ & 3.073 & 3.276 & 3.429 & 3.352 & 3.225 & 3.276 \\
\hline $858-4-4 ”$ & 3.251 & 3.505 & 3.530 & 3.657 & 3.403 & 3.479 \\
\hline $858-3-8 ”$ & 2.209 & 2.336 & 2.184 & 2.463 & 2.159 & 2.235 \\
\hline
\end{tabular}

where

$\mathrm{a} 6=[\mathrm{a} 1+\mathrm{a} 5] / 2+[\mathrm{a} 2+\mathrm{a} 4] / 2+[\mathrm{a} 3] / 3 \ldots \ldots \ldots \ldots$ Eqn $(3.3)$

Tada's empirical equation [18] was used to calculate $K$, the maximum value of $K$ when the specimen breaks was considered to be the cracking resistance (Fracture toughness) of the material.

$$
K=\frac{P}{B \sqrt{W}} \frac{\sqrt{2 \tan \left(\frac{\prod a}{2 w}\right)}}{\cos \left(\frac{\prod a}{2 w}\right)}\left[0.752+2.02\left(\frac{a}{w}\right)+0.37\left(1-\sin \frac{\prod a}{2 w}\right)\right]^{3} \ldots \ldots . \operatorname{Eqn}(3.4)
$$


Where $\mathrm{K}$ is $\mathrm{K}_{\mathrm{Q}}$ at maximum load. $\mathrm{B}$ is the thickness of the specimen, $\mathrm{W}$ is width of the specimen and $a$ is the precrack length which is obtained from ASTM E 399(a6) and $P$ is the thermal load.

\subsection{Preparation of metallographic specimens:}

As the microstructure is a function of both alloy composition and solidification rate, the microstructure needs to be analyzed for different alloy composition and solidification rates. The specimens at different locations were examined under optical microscope, scanning electron microscope to evaluate the effects of alloy composition and solidification rate on microstructure.

Rotating saw was used to cut the specimens and samples were prepared from those specimens. Then the samples were ground with 300,600 and 800 grit sand papers, and polished using 1-micron alumina powder. The samples were then etched with Keller's reagent ( $\mathrm{HCL}-1.5 \mathrm{ml}, \mathrm{HNO}_{3}-2.5 \mathrm{ml}, \mathrm{HF}-1 \mathrm{ml}$, water-95ml) for $15-20$ seconds. Scanning electron microscope (SEM), optical microscope were used to examine the microstructures and pictures were taken.

\subsection{Quantitative analysis:}

The pictures taken were then subjected to quantitative analysis. The microstructure, which includes grain size and eutectic phases were analyzed. The grain size and the area fraction of eutectics were determined using image analysis software to understand the variation of microstructure with the alloy composition and solidification rate. The basic purpose of quantitative analysis was to explain the effects of microstructure on the solidification cracking resistance of alloys. 


\subsection{Fractography:}

Fractography is analyzing the fractured specimen and predicting the reasons for fracture. The specimens were cut with a rotating saw and the fractured surfaces were observed under a scanning electron microscope. 


\section{CHAPTER 4}

\section{RESULTS}

The measured experimental results on the two DS alloys 2024 and 3004 are presented in three aspects:

1) Quench cracking resistance

2) Microstructures including grain size and fraction of eutectics segregated.

3) Fracture surfaces

\subsection{Quench cracking resistance:}

As said earlier the specimens were held on MTS and heated upto required temperature $\left(454.4^{\circ} \mathrm{C}\right)$. The load was kept very low at the beginning but after the start of the cooling the MTS was switched to displacement control and quenching using natural cooling rate was selected.

779857-3-1"

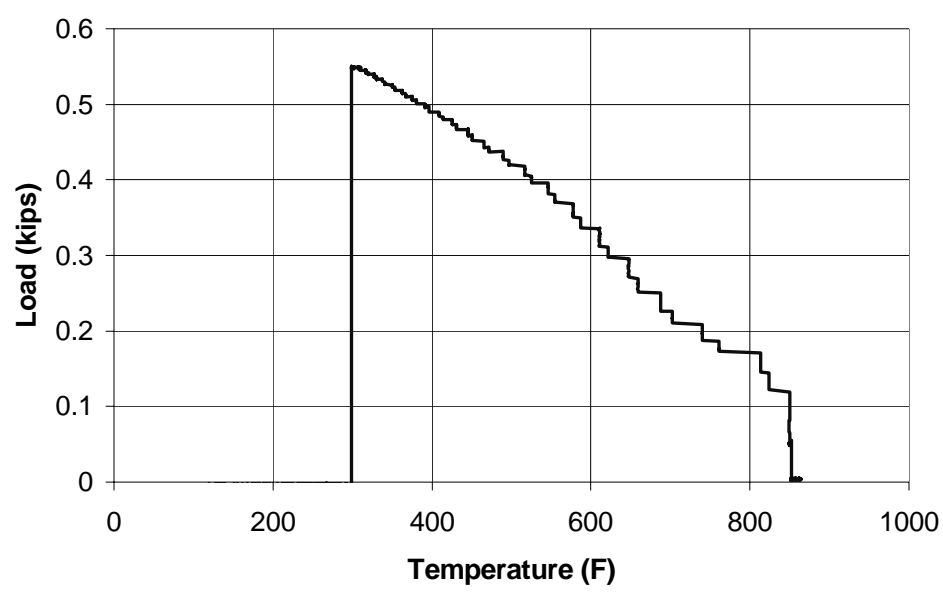

Figure 4.1 Thermal load -Temperature Curve for Al 2024 
With the decrease in temperature the quenching stress (load) on the specimen induced by the thermal contraction increased as shown in the Figure 4.1.The stress intensity factor $\mathrm{K}$ was converted from Tada's equation based on the cooling load and precrack length. Quench cracking occurs when $\mathrm{K}$ reaches a certain value at which maximum load is reached and where crack propagates rapidly occurs. This value of $\mathrm{K}$ is called the quench cracking resistance or quenches cracking toughness $\mathrm{K}_{\mathrm{Q}}$.

\subsubsection{Alloy 2024:}

All the specimens were quench cracked in the manner as discussed above and the variation of the cracking resistance with the solidification rate is tabulated in table 4.1.

Table 4.1: Variation of cracking resistance with solidification rate for 2024 alloys

\begin{tabular}{|c|c|c|c|}
\hline $\begin{array}{c}\text { SOLIDIFICATION RATE } \\
\left({ }^{\circ} \mathrm{C} / \mathrm{S}\right)\end{array}$ & $\begin{array}{c}\mathrm{K}_{\mathrm{Q}} \text { (CRACKING RESISTANCE) } \\
\mathrm{Mpa} \sqrt{m}\end{array}$ & $\begin{array}{c}\text { PRECRACK LENGTH } \\
(\mathrm{mm})\end{array}$ & $\begin{array}{l}\text { LOAD } \\
(\mathrm{KN})\end{array}$ \\
\hline 8.6 & 19.41 & 2.209 & 2.44 \\
\hline 4.44 & 16.72 & 2.057 & 2.32 \\
\hline 0.77 & 14.63 & 2.159 & 1.77 \\
\hline 0.048 & 11.7 & 1.905 & 1.82 \\
\hline 0.048 & 12.2 & 1.930 & 1.86 \\
\hline
\end{tabular}

Where $\mathrm{Load}_{M}$ is the max load.

The stress-concentration factor-temperature curves for all 2024 specimens are given in the Appendix. 


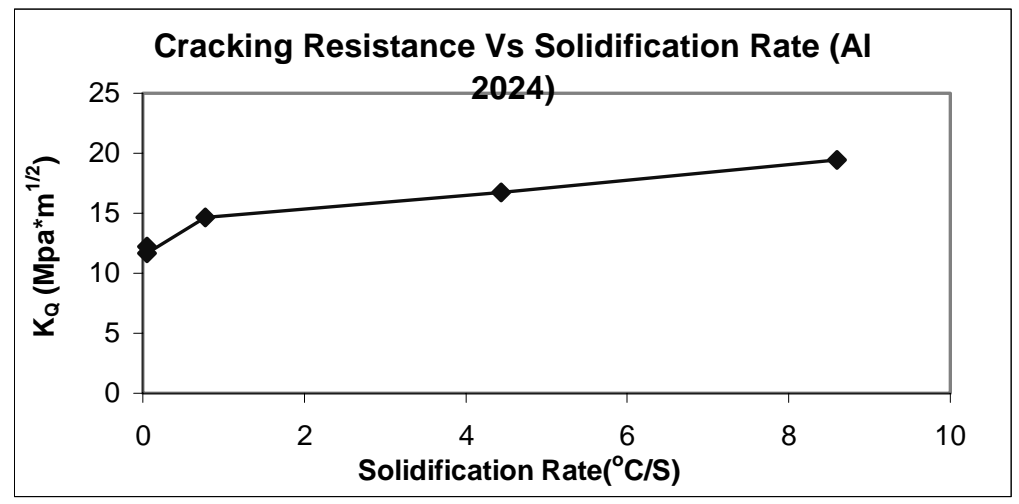

Figure 4.2 Cracking Resistance Vs Solidification Rate for 2024 Alloys



Figure 4.3 Comparison of Fracture Toughness for 2024 Alloys

It can be seen from the figure 4.2 that as the solidification rate increases the cracking resistance also increases for 2024 alloys. It was observed that for most of the specimens the crack propagated very rapidly to failure as soon as the stress concentration value reached the fracture toughness value. 
The quench cracking toughness of two specimens with the same solidification rates of 2024 Alloys were compared as shown in the figure 4.3. It was observed that the fraction toughness values differed by 0.5 . Hence the results of quench cracking tests were considered accurate with 0.5 experimental scatter.

\subsubsection{Alloy 3004}

Quench cracking tests were carried out on all the specimens of 3004 Alloys. The stress concentration factor-temperature curves for 3004 are given in the appendix and the variation of cracking resistance with solidification rate is given below in table 4.2.

Table 4.2: Variation of cracking resistance with solidification rate for 3004 Alloys

\begin{tabular}{|c|c|c|c|}
\hline $\begin{array}{c}\text { SOLIDIFICATION RATE } \\
\left({ }^{\circ} \mathrm{C} / \mathrm{S}\right)\end{array}$ & $\begin{array}{c}\mathrm{K}_{\mathrm{Q}} \text { (CRACKINGRESISTANCE) } \\
\mathrm{Mpa} \sqrt{m}\end{array}$ & $\begin{array}{c}\text { PRECRACK LENGTH } \\
(\mathrm{mm})\end{array}$ & $\begin{array}{l}\text { LOAD }_{\mathrm{M}} \\
(\mathrm{KN})\end{array}$ \\
\hline 4.44 & 37.8 & 4.292 & 1.02 \\
\hline 0.77 & 22.9 & 3.276 & 1.42 \\
\hline 0.77 & 22.5 & 3.479 & 1.15 \\
\hline 0.048 & 16.2 & 2.235 & 1.88 \\
\hline
\end{tabular}

Where load $_{M}$ is max load. 


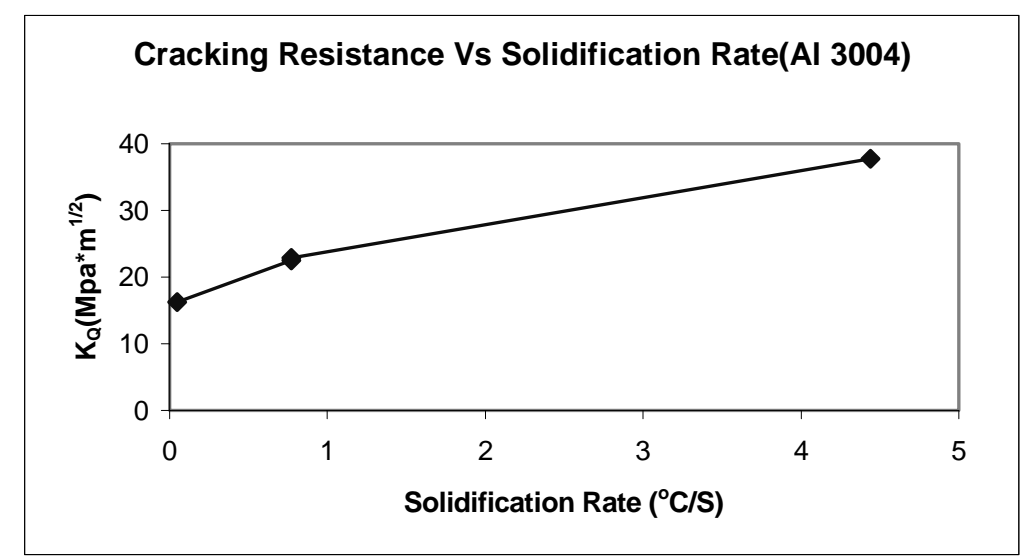

Figure 4.4 Cracking Resistance Vs Solidification rate for 3004 Alloys

From the figure 4.4 we can clearly see that cracking resistance increases with the increase in solidification rate for 3004 Alloys. Two specimens of 3004 alloy having the same solidification rates were compared as shown in the figure 4.5 and the change in their cracking resistance was observed to be 0.4 .

In both 2024 and 3004 alloys it was observed that for some specimens the load was not seen to constantly increase, this might be due to very short precrack lengths. Because of improper loading also there might not be an immediate contact between the pins and MTS machine due to which the load profile maintains a low value until there is contact between the specimens and MTS machine. But however comparing the slopes of load profiles of all the specimens, they were found to be parallel. Hence we can say that the tests were accurate with 0.5 scatter. 


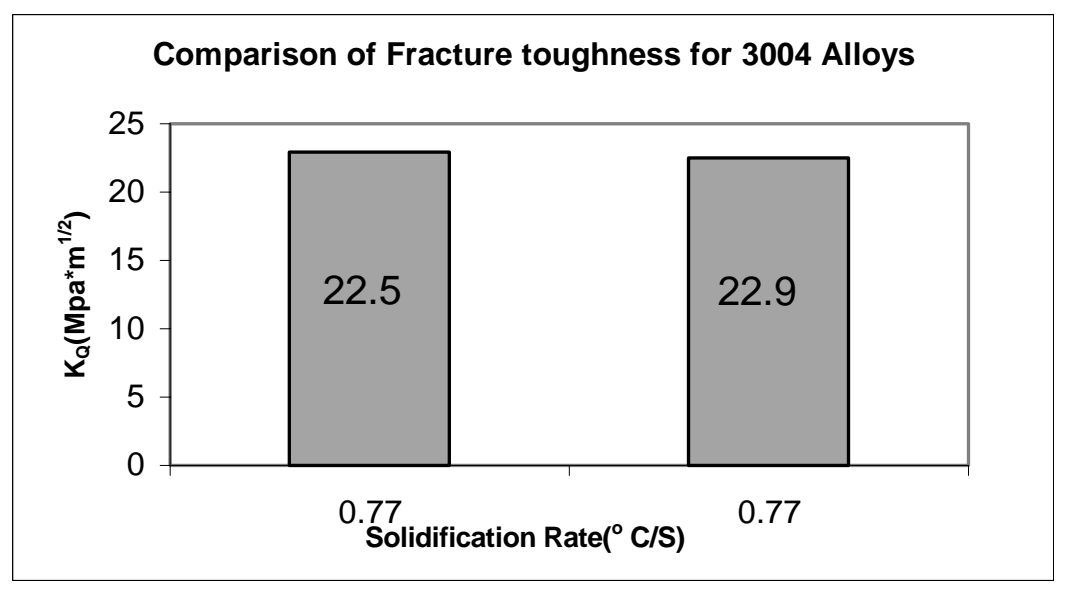

Figure 4.5 Comparison of fracture toughness for 3004 Alloys

The effect of alloy composition can be clearly observed as for the same solidification rate there is a change in cracking resistance between 2024 and 3004 Alloys. To delve into the reason microstructure analysis is very much necessary.

\subsection{Cast Microstructures:}

The microstructure is not uniform throughout the ingot as the cooling is uneven during DC casting. The as-cast structure of aluminum alloy generally consists of an array of grains having a dendrite structure. Primary aluminum surrounded by heavily cored solid solution regions essentially form the as cast structure. According to Chang et al. [7] the cooling rate during solidification is responsible for the grain sizes and eutectic phases whereas the cooling rate during continuous cooling determines the precipitation, which might affect the strength of the alloys. 


\subsubsection{Cast Microstructure for 2024 Alloys:}

According to literature in 2024 alloys primary Al-rich solid solution (a) with a dendrite structure forms the matrix. The major constituents in the microstructure are $\mathrm{Al}_{2} \mathrm{Cu}$ phase $(\theta), \mathrm{Al}_{2} \mathrm{CuMg}(\mathrm{s})$ and the ternary eutectic $(\alpha+\theta+\mathrm{s})$.



Al 2024 DS $25.4 \mathrm{~mm}$

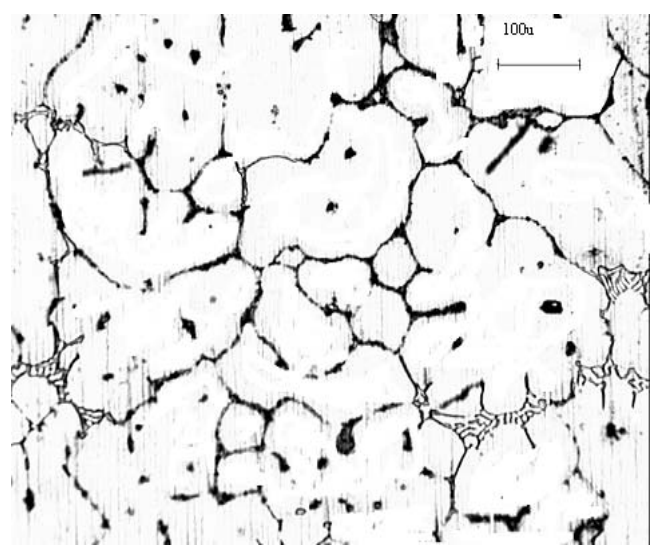

AL 2024 DS 101.6mm



Al 2024 DS 50.8mm

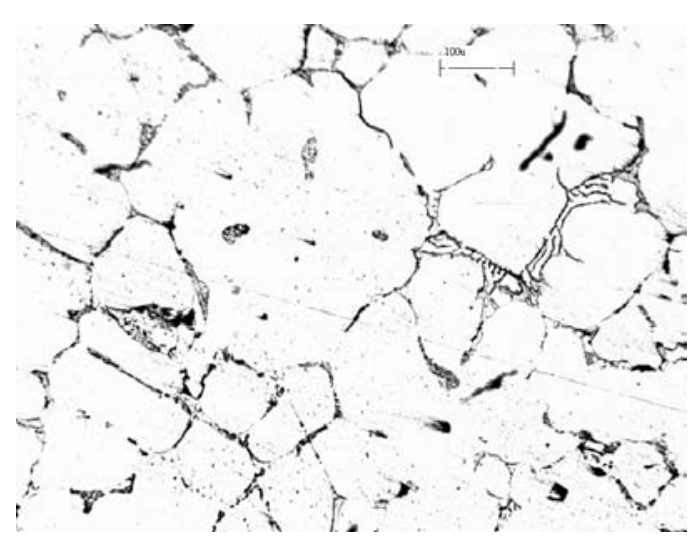

Al 2024 DS 203.2mm

Figure 4.6 Microstructures at different locations for 2024 Alloys 
Figure 4.6 shows the optical micrograph of as-cast 2024 alloys having different solidification rates. It can be seen that with the increase of solidification rate the size of primary aluminum, solid solution dendritic branches is decreased. Even the dendrite arm spacing and the size of the interdendritic particles were also observed to decrease.

The average grain diameter $\left(D_{A}\right)$ was found out by using Jeffries planimetric method and the variation of average grain size with the solidification rate is tabulated.

The ASTM grain size number $G$ can be calculated from the following relationship

$$
G=\left[3.322 \log \left(D_{A}\right)^{2}\right]-2.95
$$

Table 4.3: Variation of Grain size with Solidification Rate for 2024 Alloys

\begin{tabular}{|c|c|c|}
\hline $\begin{array}{l}\text { LOCATION OF THE } \\
\text { SPECIMEN }(\mathrm{mm})\end{array}$ & $\begin{array}{l}\text { GRAIN SIZE } \\
\text { (Microns) }\end{array}$ & $\begin{array}{c}\text { SOLIDIFICATIONRATE } \\
\left({ }^{\circ} \mathrm{C} / \mathrm{S}\right)\end{array}$ \\
\hline 25.4 & 120.7 & 8.6 \\
\hline 50.8 & 202.2 & 4.44 \\
\hline 101.6 & 279.8 & 0.77 \\
\hline 203.2 & 375 & 0.048 \\
\hline
\end{tabular}

It can be observed from table 4.3 that with the increase in solidification rate the grain size becomes finer. Figure 4.7 shows the variation of grain size with solidification rate for 2024 alloys. To analyze the eutectic phases segregated in Al 2024 pictures were taken with SEM at magnification of $100 \mathrm{X}$ and $1000 \mathrm{X}$ and are shown in figure 4.8 . 
Figure 4.7 shows the variation of grain size with solidification rate for AI 2024 alloys.

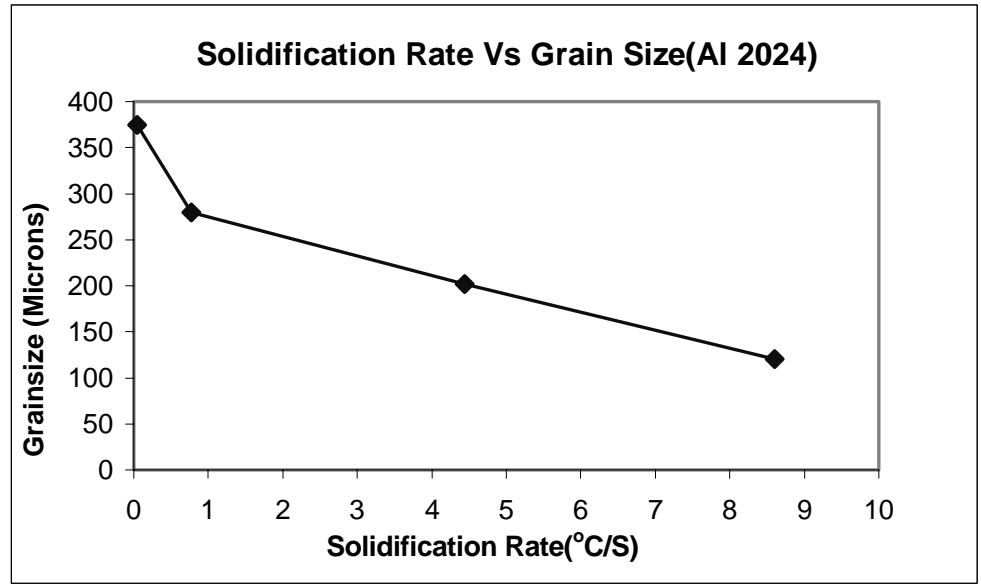

Figure 4.7 Solidification Rate Vs Grain size for 2024 Alloy

To analyze the eutectic phases segregated in Al 2024 pictures were taken with SEM at magnification of $100 \mathrm{X}$ and $1000 \mathrm{X}$ and are shown in figure 4.8.

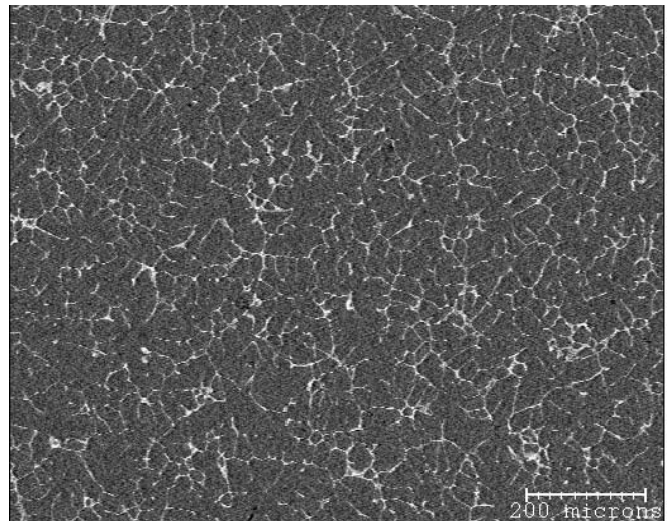

Al 2024 DS 25.4mm (100X)

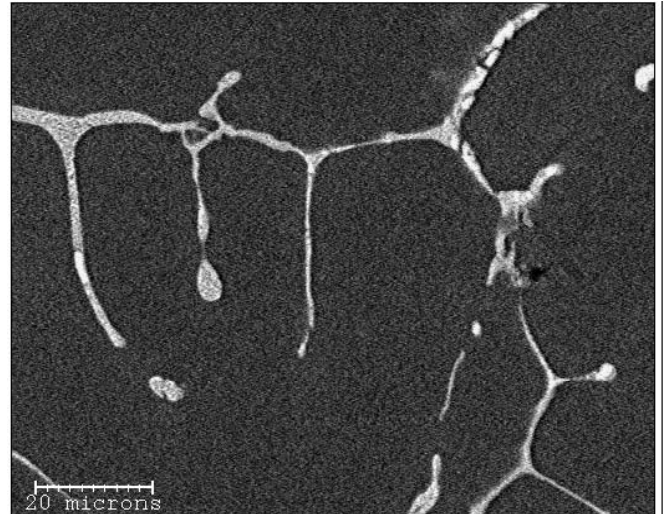

Al 2024 DS 25.4mm (1000X) 


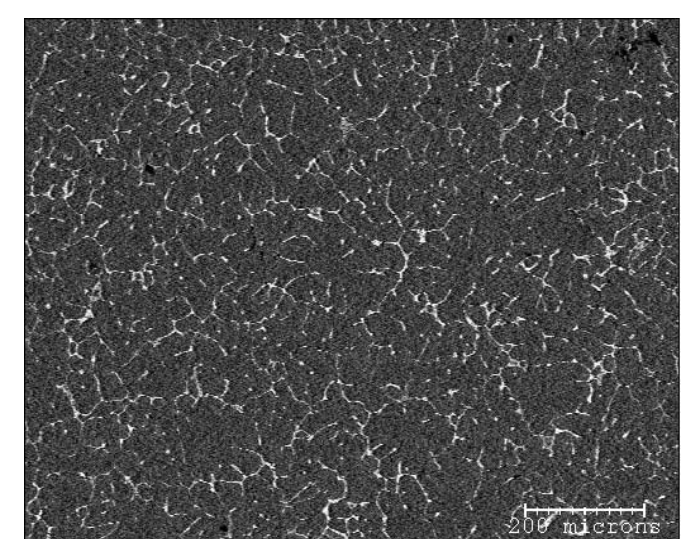

Al 2024 DS 50.8mm (100X)

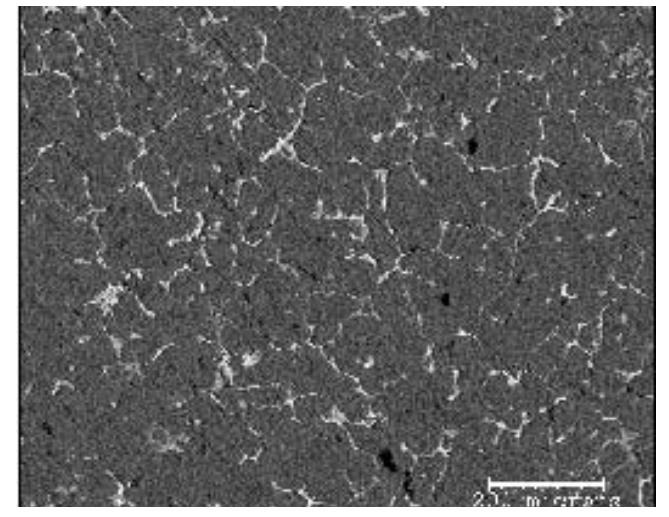

Al 2024 DS 101.6mm (100X)

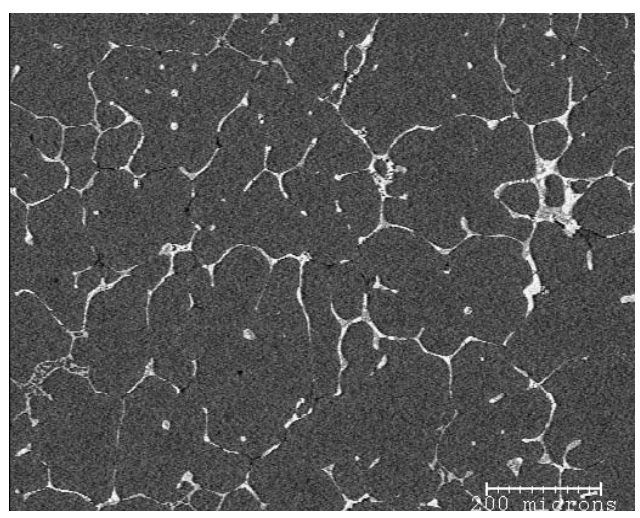

Al 2024 DS 203.2mm (100X)



Al 2024 DS 50.8 mm (1000X)

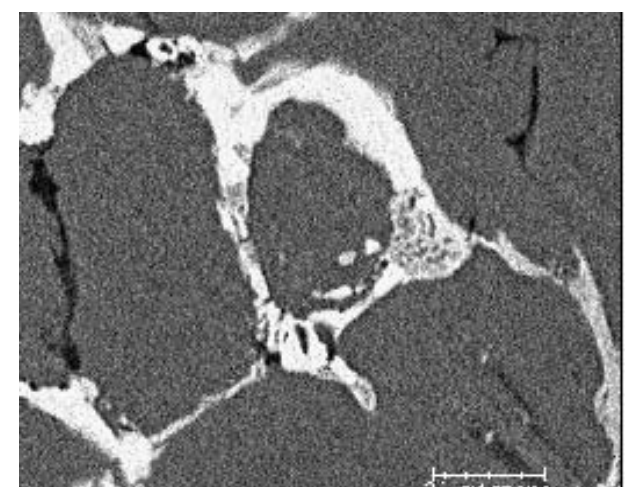

Al 2024 DS 101.6mm (1000X)

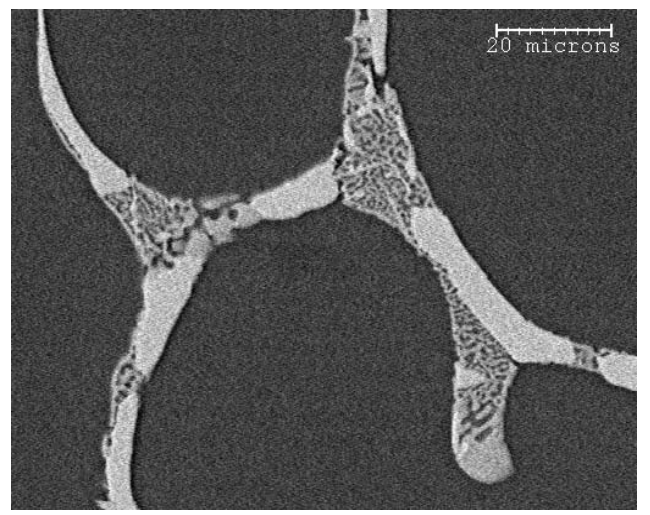

Al 2024 DS 203.2mm (1000X)

Figure 4.8: SEM pictures of 2024 Alloys at different locations 
The black areas in the above pictures are primary Al-rich solid solution (a), the bright areas being $\mathrm{Al}_{2} \mathrm{Cu}$ phase $(\theta)$ and the other area is the ternary eutectic. From the above figure it can be observed that the dendrites are either separated by $\theta$ and ternary eutectic or they are in touch with each other. The fraction of the eutectics segregated at the grain boundaries was also observed to be considerably more than the eutectics inside the grain. It was seen that the eutectic phases segregated at the grain boundaries were thin for specimen with fast cooling rates and coarse for specimen with slow cooling rates. The fraction of the eutectics segregated at the grain boundaries for Al 2024 were considered as the total fraction of eutectics and were calculated by using image analyzer software. Their variation with the solidification rates is tabulated.

Table 4.4: Variation of Fraction of Eutectics with solidification rate for 2024 Alloys

\begin{tabular}{|c|c|c|}
\hline $\begin{array}{l}\text { LOCATION OF THE } \\
\text { SPECIMEN }(\mathrm{mm})\end{array}$ & $\begin{array}{l}\text { AREA FRACTION OF } \\
\text { EUTECTICS }(\%)\end{array}$ & $\begin{array}{c}\text { SOLIDIFICATION RATE } \\
\left({ }^{\circ} \mathrm{C} / \mathrm{S}\right)\end{array}$ \\
\hline 25.4 & 2.9 & 8.6 \\
\hline 50.8 & 4.1 & 4.44 \\
\hline 101.6 & 5.1 & 0.77 \\
\hline 203.2 & 8 & 0.048 \\
\hline
\end{tabular}

From table 4.4 we can observe that as the solidification rate increased the fraction of the eutectics segregated at the grain boundaries decreased. The eutectics segregated in specimens with low solidification rate were observed to be continuous and very coarse. 
Figure 4.9 shows the variation of the solidification rate with the area fraction of the eutectics.

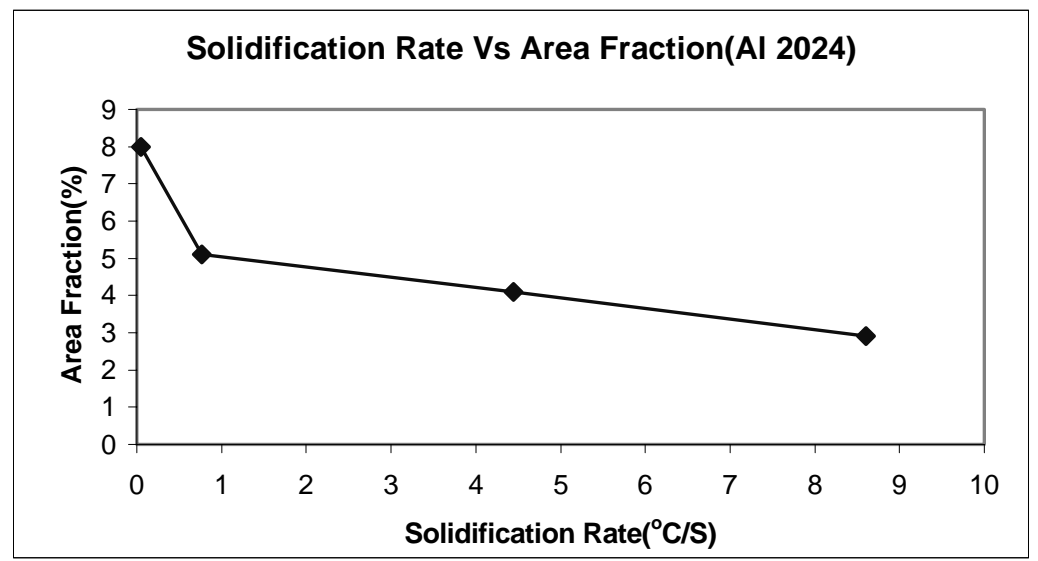

Figure 4.9 Solidification Rate Vs Area fraction of Eutectics for 2024 Alloy

\subsubsection{Cast microstructure for 3004 Alloys:}

The cast microstructure of 3004 Alloys mainly consists of primary aluminum with dendritic structure having different constituent phases at dendrite cell boundaries. The main constituent phases in as cast structure of $\beta-\mathrm{Al}_{6}(\mathrm{Fe}, \mathrm{Mn})$ and $\mathrm{Mg}_{2} \mathrm{Si}$. The silicon containing $\alpha-\mathrm{Al}_{15}(\mathrm{Fe}, \mathrm{Mn})_{3} \mathrm{Si}_{2}$ which is formed by the peritectic reaction from $\mathrm{Al}_{6}(\mathrm{Fe}$, $\mathrm{Mn}$ ) is present in very small quantity in ingot. According to Rouns et al. [18] less amount of $\alpha-\mathrm{Al}_{15}(\mathrm{Fe}, \mathrm{Mn})_{3} \mathrm{Si}_{2}$ is formed at faster cooling rates as rapid cooling suppresses the diffusion controlled peritectic reaction. It was also observed from the literature [8] that the morphology of $\alpha-\mathrm{Al}_{15}(\mathrm{Fe}, \mathrm{Mn}){ }_{3} \mathrm{Si}_{2}$ and $\beta-\mathrm{Al}_{6}(\mathrm{Fe}, \mathrm{Mn})$ are same and it is very difficult to distinguish between the two phases. The binary eutectic formed in 3004 alloys is $\mathrm{Al}_{+} \mathrm{Al}_{6}$ (Fe, Mn) and the ternary eutectic formed is $\mathrm{Al}+\mathrm{Al}{ }_{15}(\mathrm{Fe}, \mathrm{Mn})_{3} \mathrm{Si}_{2}+\mathrm{Mg}_{2} \mathrm{Si}$. 


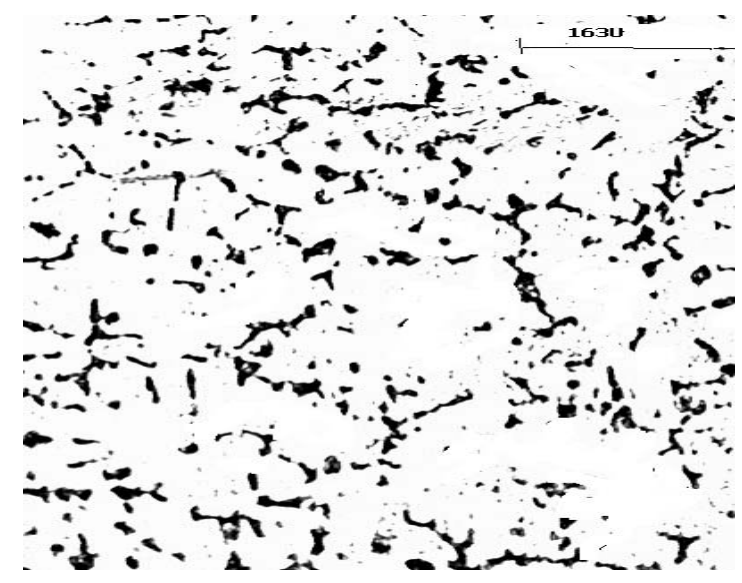

Al 3004 DS 50.8mm

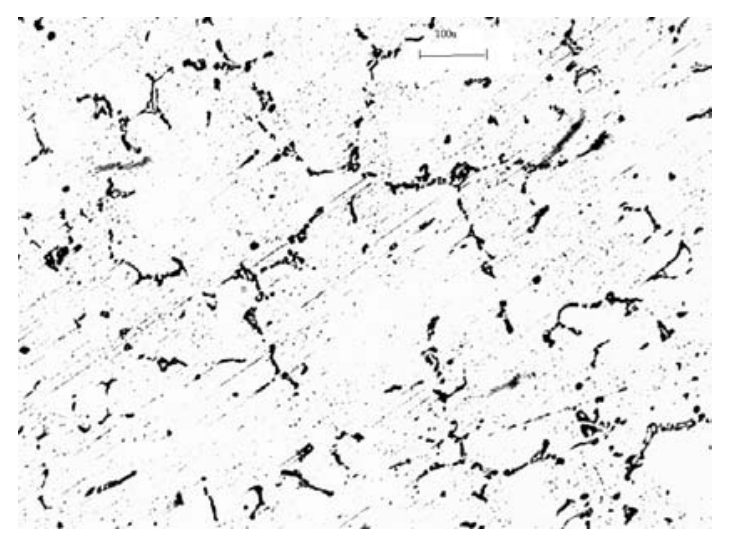

Al 3004 DS 101.6mm

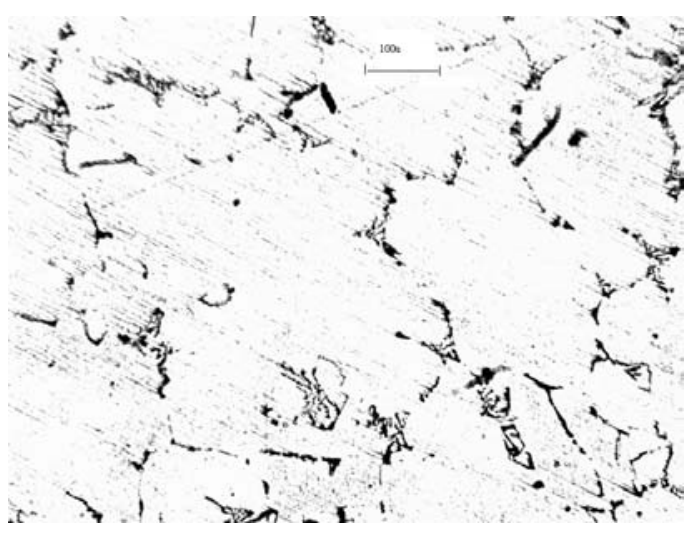

Al 3004 DS 203.2mm

Figure 4.10: Microstructures at different locations for 3004 Alloys

Figure 4.10 shows the optical micrograph of as-cast 3004 alloys having different solidification rates. The average grain diameter $\left(D_{A}\right)$ was found out by using Jeffries planimetric method and the variation of average grain size with the solidification rate is tabulated. 
Table 4.5 Variation of Grain size with Solidification Rate for 3004 Alloys

\begin{tabular}{|c|c|c|}
\hline $\begin{array}{c}\text { LOCATION OF THE } \\
\text { SPECIMEN }(\mathrm{mm})\end{array}$ & $\begin{array}{c}\text { SOLIDIFICATION RATE } \\
\left({ }^{\circ} \mathrm{C} / \mathrm{S}\right)\end{array}$ & $\begin{array}{c}\text { GRAIN SIZE } \\
(\text { MICRONS })\end{array}$ \\
\hline 50.8 & 4.44 & 195.2 \\
\hline 101.6 & 0.77 & 274.1 \\
\hline 203.2 & 0.048 & 365.1 \\
\hline
\end{tabular}

It can be seen from figure 4.10 that with the increase in solidification rate the constituent phase particles between the dendrites and the dendrite cell boundaries become finer. It can also be observed that the dendrite arm spacing decreases and the constituent particles tend to become round with the increase of solidification rate.



Figure 4.11: Solidification rate Vs. Grain size for 3004 Alloy

From Figure 4.11 it can be observed that the grain size decreases with the increase in solidification rate. 
To analyze the eutectic phases segregated during solidification pictures of specimens at different locations were taken in scanning electron microscope (SEM) at magnifications of $100 \mathrm{X}$ and $1000 \mathrm{X}$.



Al 3004 DS 101.6mm(100X)

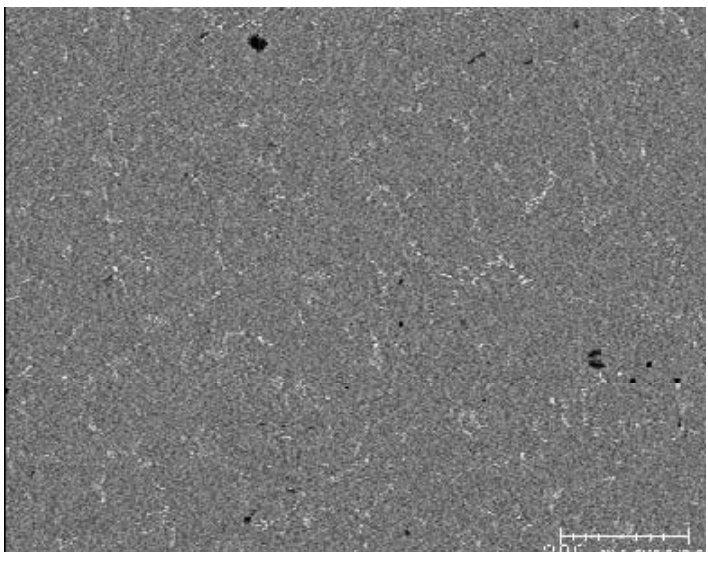

Al 3004 DS 50.8mm(100X)



Al 3004 DS 101.6mm(1000X)

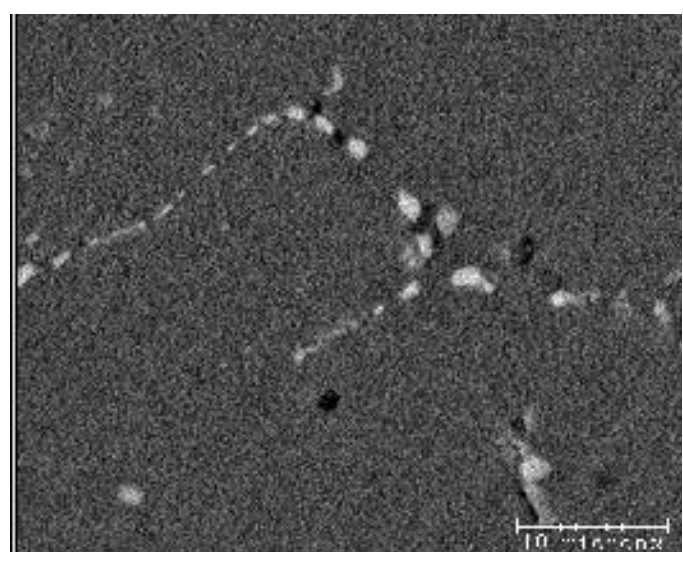

Al 3004 DS 50.8mm(1000X) 


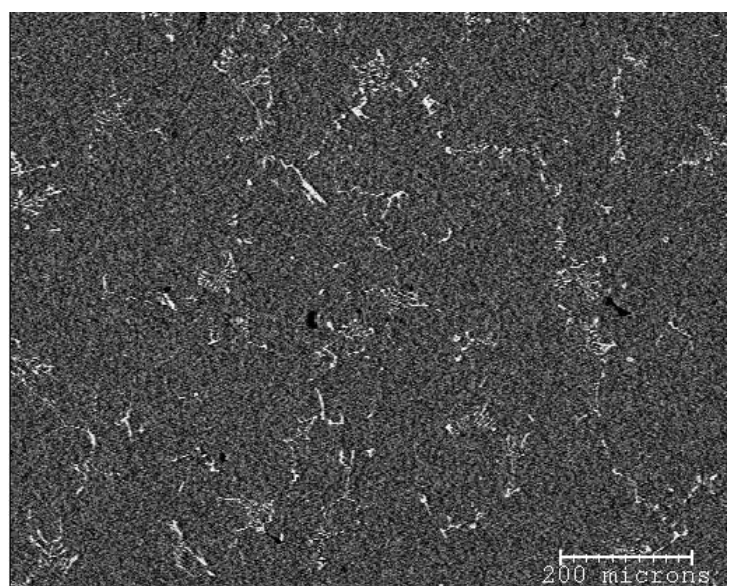

Al 3004 DS 203.2mm(100X)



Al 3004 DS 203.2mm(1000X)

Figure 4.12 Microstructure at different locations for 3004 using SEM

From Figure 4.12 it can be seen that there were some eutectic phases segregated inside the grain in addition to the ones segregated at the grain boundaries. When compared with figure 4.8 it was observed that the eutectic phases segregated in 3004 were very lesser than that of 2024. It can also be seen that the fraction of eutectics (both inside the grain and at the grain boundaries) increased with the decrease of solidification rate. The total area fraction of eutectics segregated (inside and at the grain boundaries) were calculated using Image analyzer software and their variation with solidification rate is tabulated as shown below in table 4.6. 
Table 4.6: Variation of Eutectics with Solidification Rates for 3004 Alloys

\begin{tabular}{|c|c|c|}
\hline $\begin{array}{l}\text { LOCATION OF THE } \\
\text { SPECIMEN }(\mathrm{mm})\end{array}$ & $\begin{array}{l}\text { AREA FRACTION OF } \\
\text { EUTECTICS (\%) }\end{array}$ & $\begin{array}{c}\text { SOLIDIFICATION RATE } \\
\left({ }^{\circ} \mathrm{C} / \mathrm{S}\right)\end{array}$ \\
\hline 50.8 & 0.8 & 4.44 \\
\hline 101.6 & 2.5 & 0.77 \\
\hline 203.2 & 6.1 & 0.048 \\
\hline
\end{tabular}

Figure 4.13 shows the variation of eutectic phases with solidification rate for Al 3004 alloys.



Figure 4.13 Solidification Rate Vs Fraction of Eutectics

It was observed that with the increase in solidification rate the fraction of the eutectics segregated decreased for 3004 Alloys. 


\subsection{Fracture surfaces:}

The study of fracture surfaces to determine the type of fracture and the way in which fracture takes place is called Fractography. The Fracture surfaces of 2024 and 3004 Alloys were carefully examined by using SEM.
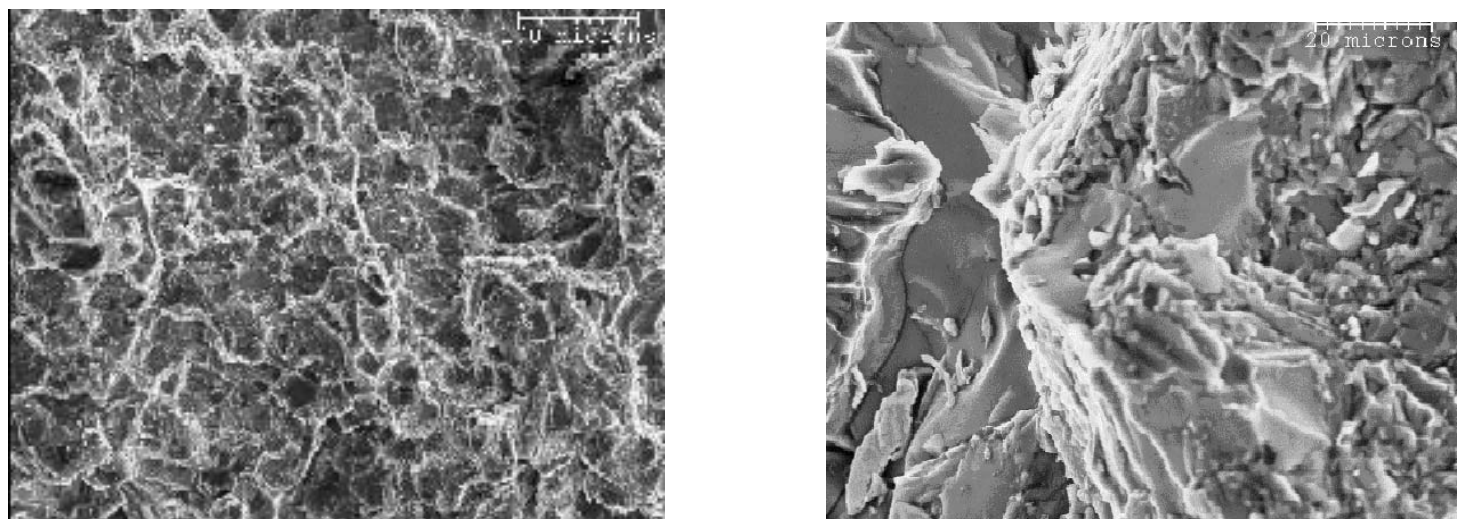

Figure 4.14 Intergranular Fracture of 2024 Alloys

From figure 4.14 it can be seen that the fracture in 2024 alloys was mostly intergranular, it was associated with the crack propagation through the eutectic phases segregated at the grain boundaries.
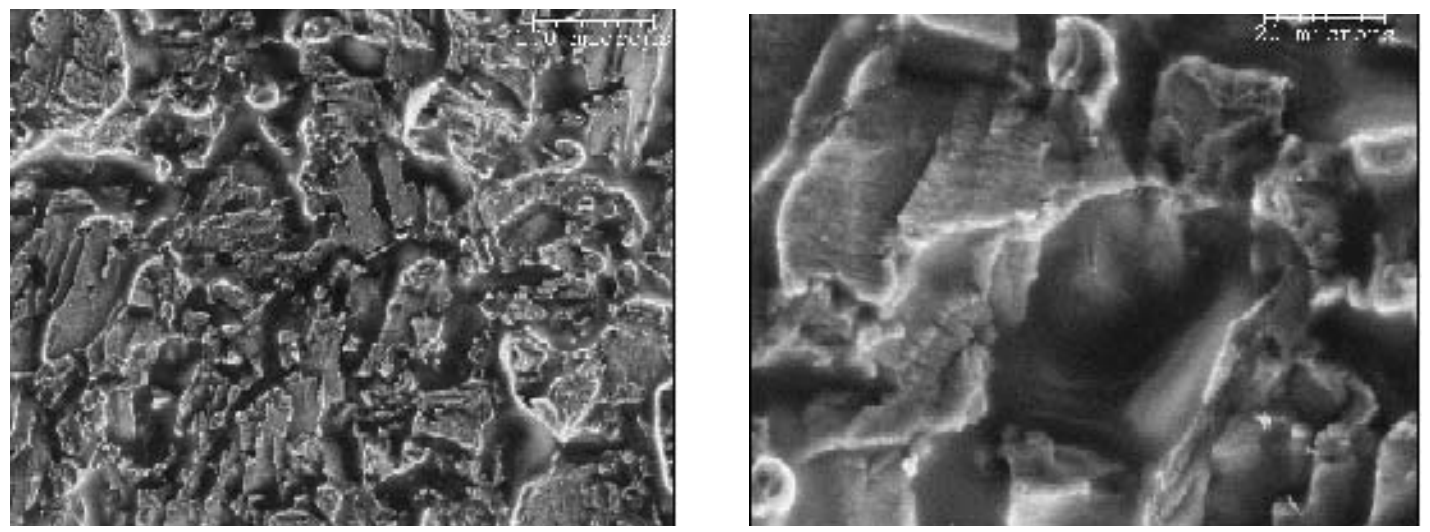

Figure 4.15 Transgranular Fracture of 3004 Alloys 
From the figure 4.15 it can be observed that the fracture was of mixed type majority being transgranular, the crack propagated through the grains. 


\section{CHAPTER 5}

\section{DISCUSSION}

The results are discussed in this chapter by comparing Al 2024 and Al 3004 Alloys in

(1) Cracking resistance and

(2) Microstructure.

In addition the alloys are also compared with other high strength aluminum alloys like 7050 and 7075 . The influence of alloy composition on microstructure is emphasized and the effects of microstructure on cracking resistance are discussed.

\subsection{Comparison of Cracking resistance (2024 Vs 3004alloys):}

The first step to illustrate the effect of alloy composition on microstructure is the comparison of cracking resistance of both 2024 and 3004 alloys at same solidification rates.

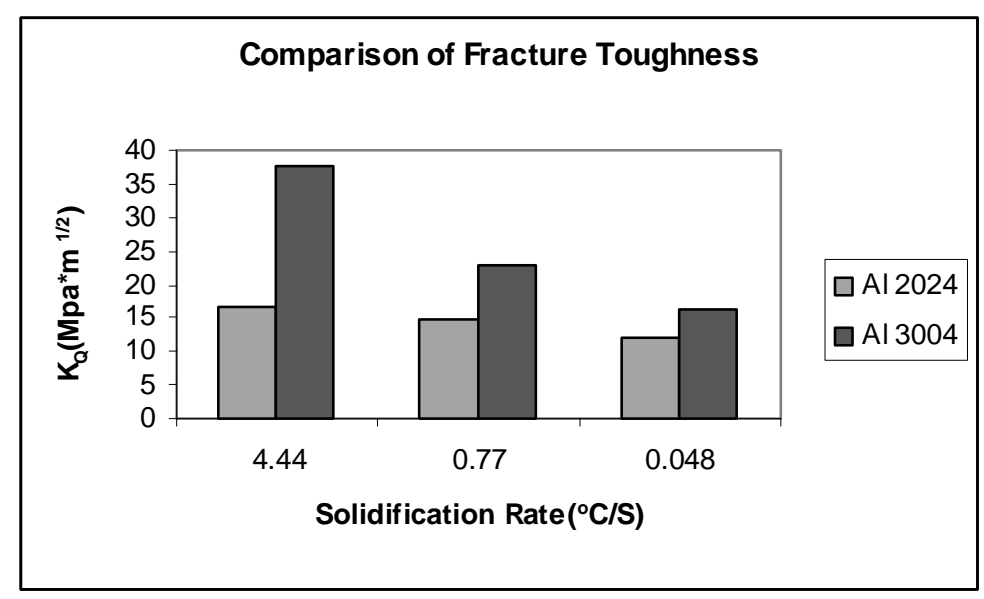

Figure 5.1 Comparison of Fracture Toughness (2024 Vs 3004) 
From Figure 5.1 it can be observed that for the same solidification rate the cracking resistance of 3004 is more than 2024. To delve into the reason, comparison of microstructures was very much essential.

\subsection{Comparison of Microstructure (2024 Vs 3004 alloys):}

Microstructure essentially comprises the grain size and the fraction of eutectics segregated during solidification. From the results we have seen that solidification rate plays an important role in deciding the microstructure and the microstructure changes with the solidification rate.

Microstructure of 2024 and 3004 is compared at same solidification rates.



Figure 5.2 Comparison of Grain size (2024 Vs 3004)

I

It was observed that the grain sizes were almost similar for both the alloys for different solidification rates from figure 5.2.

As the fraction of eutectics segregated inside the grain is very less for 2024 Alloy, it is neglected and the fraction of eutectics segregated at the grain boundaries is taken as fraction of total eutectics segregated during solidification. 




Figure 5.3 Comparison of Fraction of Eutectics (2024 Vs 3004)

From the Figures 5.2 and 5.3 we can see that at the same solidification rate the microstructure of Al 2024 is different from Al 3004. Though the grain sizes are almost similar there is a vast difference in the fraction of eutectics segregated during solidification, for the same cooling rate. Hence it is clear that microstructure not only depends on solidification rate but also on the alloy composition, which is responsible for the formation of eutectics. Hence it is seen and that microstructure is a function of both solidification rate and alloy composition.

\subsection{Comparison with Alloys in Literature:}

The cracking resistance of 2024 and 3004 Alloys was compared to that of other high strength aluminum alloys like 7050 and 7075 Alloys (Al-Zn-Cu-Mg) obtained from the literature [2] for almost the same solidification rate. 


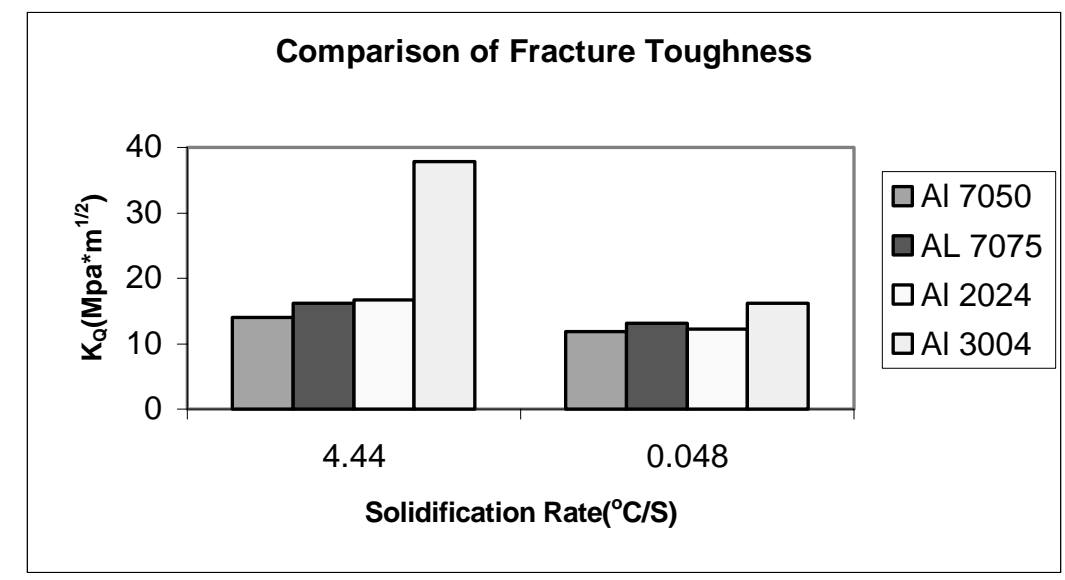

Figure 5.4 Comparison of Fracture toughness for different high strength Alloys

It can be seen that for all the alloys shown above the as the solidification rate increased the fracture toughness also increased. Al 3004 Alloy was observed to have the maximum cracking resistance when compared with the other alloys. The difference in the fracture toughness with the change in alloy composition can be clearly observed.

\subsection{Effect of Microstructure on Cracking resistance of aluminum alloys:}

We have already seen the effect of alloy composition on microstructure, now by emphasizing the effect of microstructure on cracking resistance we can illustrate the effects of alloy composition on cracking resistance.

For 2024 alloys the grain size and the fraction of eutectics segregated at the grain boundaries was observed to decrease with the increase in solidification rate. When the solidification rate was less the grain size was more, the fraction of eutectics along grain boundaries was more and moreover the eutectics were coarse and continuous. We see from the experimental results that the cracking resistance is low in this case when compared to higher solidification rates. This makes sense, as the number of grain boundaries through which the crack has to pass would be less resulting in absorption of 
less amount of cracking energy, and crack can easily pass through the coarse eutectic phases along the grain boundaries leading to an intergranular fracture. When the grain size and fraction of eutectics decreases the cracking resistance increases.

For 3004 alloys most of the fracture was observed to be of transgranular nature. It was observed that for even for 3004 alloys with the increase in solidification rate the grain size and the total fraction of eutectics segregated during solidification (both at the grain boundaries and inside the grain) decreased. When solidification rate was less for 3004 alloys the grain size was more and the fraction of eutectics inside the grain were more and the morphology of eutectics was coarse when compared to the case when solidification rate was high. We can observe from experimental results that cracking resistance is low in this case. This can be explained because when the fraction of eutectics inside the grain is more it become easier for the crack to pass when compared to the case in which the fraction of eutectics inside the grain is less. The reason why the crack is not passing through the eutectic phases in the grain boundaries inspite of the presence of a fraction of eutectic phases in grain boundaries is still unclear.

The reason for the change in cracking resistance for 2024 and 3004 alloys at the same solidification rate can be attributed to alloy composition, as the composition of the eutectic and the composition of the matrix are different and they may contain some elements which might be brittle or ductile resulting in decrease or increase in cracking resistance respectively. 


\section{CHAPTER 6}

\section{SUMMARY AND FUTURE WORKS}

Two aluminum alloys, alloy 2024 and 3004 have been used in this research and the cracking resistance of these alloys was determined using quench cracking tests developed at WVU. The two alloys were compared in microstructure and cracking resistance and the effects of the cooling rate during solidification rate and alloy composition on the cracking resistance were discussed.

A brief summary of the work done is given below

1) The Quench cracking resistance of Al 2024 and Al 3004 alloys was determined for specimens with different solidification rates during cooling by quench cracking tests developed at West Virginia university.

2) The cracking resistance was observed to increase with the increase in solidification rate for both 2024 and 3004 alloys.

3) With the increase in solidification rate (which generally decreases from surface to the center of the ingot) the grain size and fraction of eutectics segregated during solidification decreases for both 2024 and 3004 Alloys and vice versa. 
4) For the same solidification rate the cracking resistance of 3004 was observed to be more than 2024 alloys.

5) The change in fracture toughness for the same solidification rate during cooling was attributed to lesser fraction of eutectics segregated for 3004 during solidification and also to the composition of matrix and eutectics.

\section{Recommendations for future study:}

1) By changing the amount of one particular element in an alloy the effect of element on the cracking resistance can be studied.

2) Work must be done in deciding the nature (ductile or brittle) and composition of eutectics, which are very important in deciding the cracking resistance.

3) Transient and stationary phase of DC casting must be simulated three dimensionally taking into account the dependence of material properties on cooling history and temperature, and the thermal stresses should be obtained.

4) The fracture toughness at different locations of the ingot must be compared with the thermal stresses obtained to explain the different types of fracture in aluminum ingots. 


\section{REFERENCES}

[1] "The technology of Aluminum and its Alloys", Varley P.C.

[2] Jian wan, "Thermal Stress Prediction for Direct chill casting of a High strength Aluminum Alloys", PhD Dissertation, 1998 May, West Virginia University.

[3] Yaping Wu, "Numerical Analysis of Direct Chill Casting of Aluminum ingot", Masters Thesis, 1999 April, West Virginia University.

[4] Rebekah Renee Briers, "The Relationship Between Cooling Rates and Solidification Structures in High Strength Aluminum Alloys", Masters thesis, 1998 May, West Virginia University.

[5] "Aluminum, Vol. I. Properties, Physical Metallurgy and Phase Diagrams", 1967,Edit by K.R.Van Horn, American society for Metals, Metal Park, Ohio.

[6] "ASM Metal Hand book", J.R.Davis et al, Ed; Vol 2,10 $10^{\text {th }}$ Ed. (Materials Park, OH: ASM International, 1995).

[7] Lu H.M., Chang, K.M. and Harris J.; "Constitutive modeling of High Strength Aluminum Casting", Light Metals, 1997,p.1091-1095.

[8] Sun D.L, Kang S.B; Koo H.S, Characteristics of Morphology and crystal Structure of $\alpha$ phase in two Al-Mn-Mg alloys, Materials chemistry and physics, 2000,p.37-43. 
[9] F.Y.Xie, T.Kraft, "Microstructure and Micro segregation in Al-Rich Al-Cu-Mg Alloys", Scripta Metallurgica et Materiala, Vol. 30, pp.487-492, 1994.

[10] N.A Belov, "Effect of Eutectic Phases on the fracture behavior of High strength Castable Aluminum Alloys", Metals science and Heat treatment, 1995, Vol 37, P.237EOA.

[11] Upadhya G; Cheng S.; Chandra U., " A Mathematical model for prediction of Hot tears", Light Metals Proceedings, 1995,P 1101-1106.

[12] Lacaze, J; and Lesoult, G; "Experimental Investigation of the Development of Micro segregation during solidification of an Al-Cu-Mg -Si ALLOY", Material Science and Engineering, 1993,p.119-122.

[13] Chang, K. -M; and Kang, B; "Control of Solidification Cracking in High strength Aluminum alloys II", 1997 Annual Report for Century Aluminum, January 1998.

[15] "Simulation of Solidification and Viscoplastic Stresses During Vertical Semi continuous Direct Chill Casting of Aluminum Alloy", T.Inoue and D.Y.Ju, International Journal of Plasticity, Vol.8. pp.161-183.1992.

[16] "ALSPEN -A mathematical Model for Thermal Stresses in Direct Chill Casting of Aluminum Billets", Hallvard G. Fjaer and Asbjorn MO, Metallurgical Transcation B, Vol 21 B, 1990, pp 1049-1061. 
[17] H.Kraushaar, R.jeschar, V. Heidt, E.K. Jensen and W.Scheinder, "Correlation of Surface Temperature and Heat Transfer by DC casting of Aluminum Ingots" < Light Metals, 1995, ed.J.Evans, pp.1055-1059.

[18] O.P Khanna "A text book of Material science and Metallurgy".

[19] " Effects of cooling rate and grain refining on constituent phase particle size in as cast 3004 Alloy", P.N. Anyalebechi, T.N. Rouns, Light Metals 1991.

[20] J.Mao, V.L Keefer, K.M Chang and D.Furrer, "An Investigation on Quench Cracking Behavior of Super alloy Udimet 720 Li Using a Fracture mechanics Approach", Journal of Materials Engineering and Performance.

[21] Dr.A.Ghosh, "Segregation in cast Products", Indian Institute of Technology, Kanpur, India.

[22] "Heat treating Aluminum Alloys", Reynolds Metals Company.

[23] J.Sengupta,D.Maijer,M.A. Wells, S.L.Cockcroft, A.Larouche "Mathematical modeling of the thermomechanical behavior of a 5182 aluminum ingot during the startup phase of the DC casting process: The role of the bottom block". Light metals 2001,Pg no:879-885.

[24] Giron A, Chu G. "Effect of mushy zone mechanical properties on the calculated stresses and deformations during the casting of an aluminum alloy ingot". Light metals 2000, Nashville TN, p 579-584. 
[25] Fjaer Hallvard G., Mortensen Dag, Hakonsen Arild, Sorheim Einar A. " Coupled stress, thermal and fluid flow modeling of the start up phase of aluminum sheet ingot casting".Light metals 1999, p 743-748.

[26] Yang X. "Modeling of solidification of al alloys in a laboratory scale DC simulator". Light metals 2000, p 591-596.

[27] Barral P, Quintela P." Numerical method for simulation of thermal stresses during casting of aluminum slabs". Computer methods in applied mechanics and engineering, $\mathrm{V}$ $178, \mathrm{n} 1,1999, \mathrm{p} 69-88$.

[28] Longzhou Ma "Effects of Ni Al Beta precipitates of crack growth behavior in INCONEL alloy 783", Ph.D Dissertation May 2001,West Virginia University. 


\section{APPENDIX}

\section{Al. PRECRACK CURVES}

AII. QUENCH CRACK CURVES 


\section{A1.PRECRACK CURVES:}

For all the figures units of K-Mpa $\sqrt{m}, \mathbf{T}, \mathbf{W}-\mathbf{m m}$

Where K-stress intensity factor

T-thickness of the specimen

W-width of the specimen

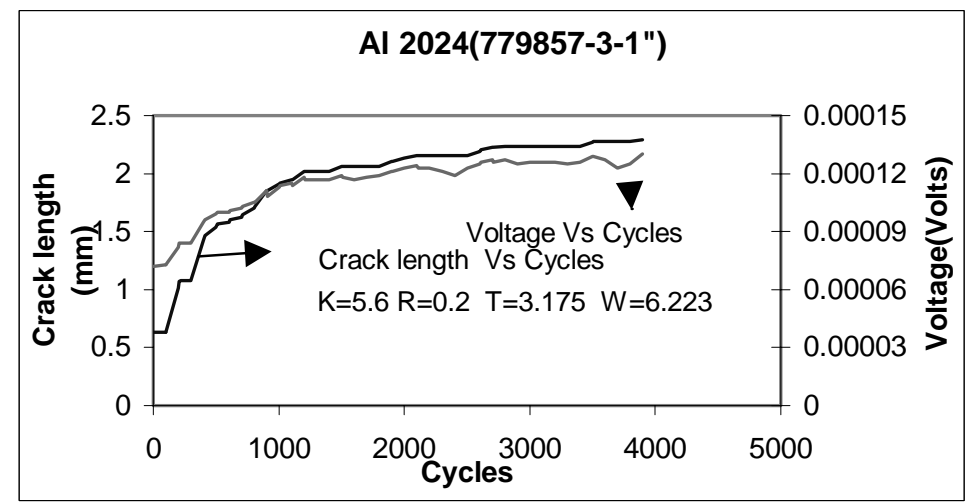

A1. Voltage, Crack length Vs No of cycles for Al 2024(779857-3-1")



A2. Voltage, Crack length Vs No of cycles for Al 2024 (779857-2 -2") 


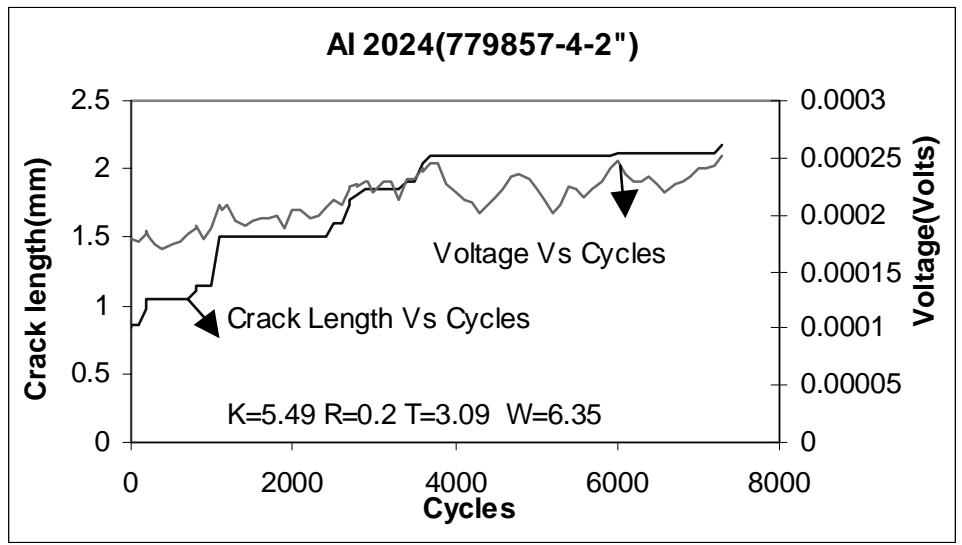

A3. Voltage, Crack length Vs No of cycles for Al 2024 (779857-4-2”)

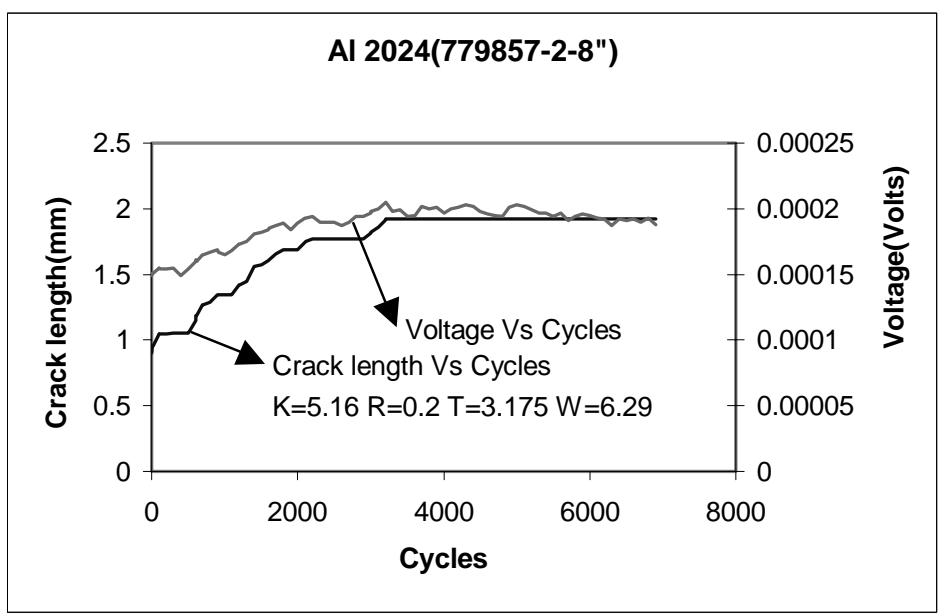

A4. Voltage, Crack length Vs No of cycles for Al 2024 (779857-2-8”) 


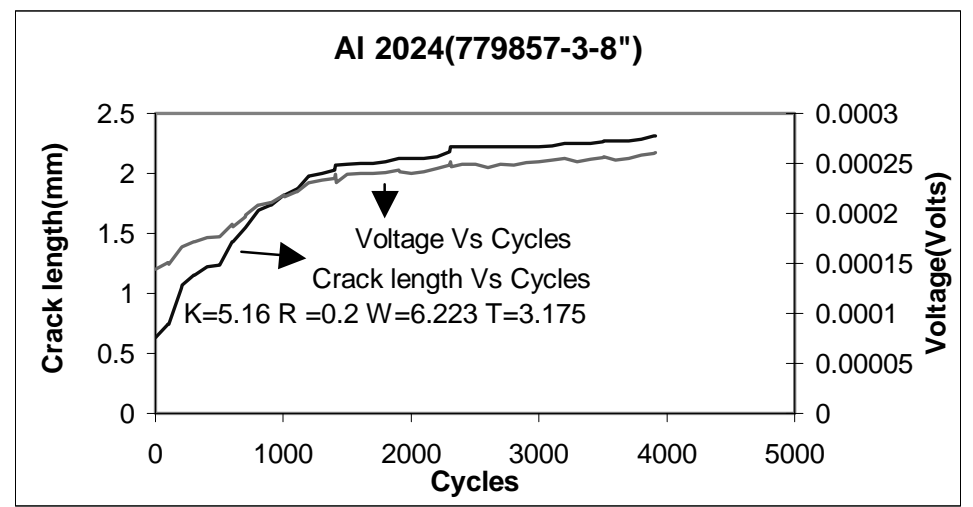

A5. Voltage, Crack length Vs No of cycles for Al 2024 (779857-3-8”)

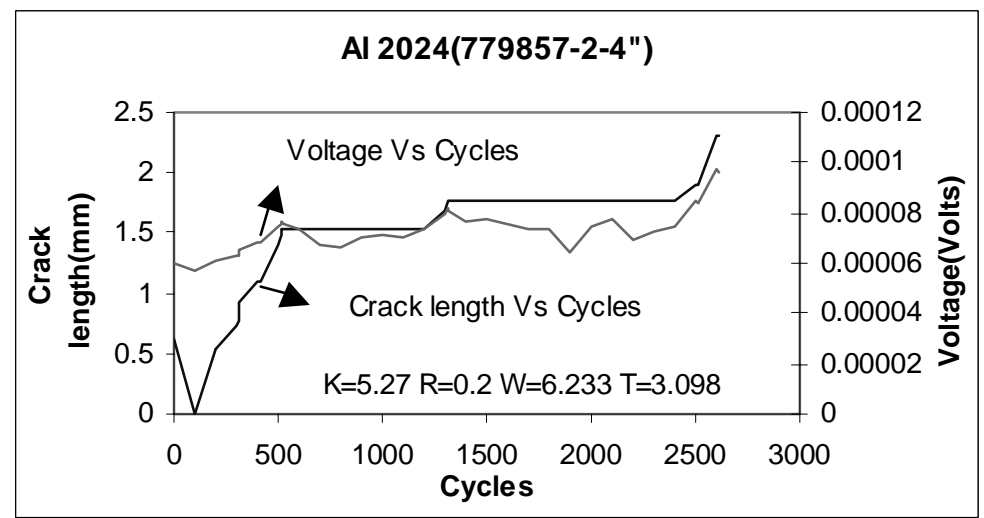

A6. Voltage, Crack length Vs No of cycles for Al 2024 (779857-2-4”) 


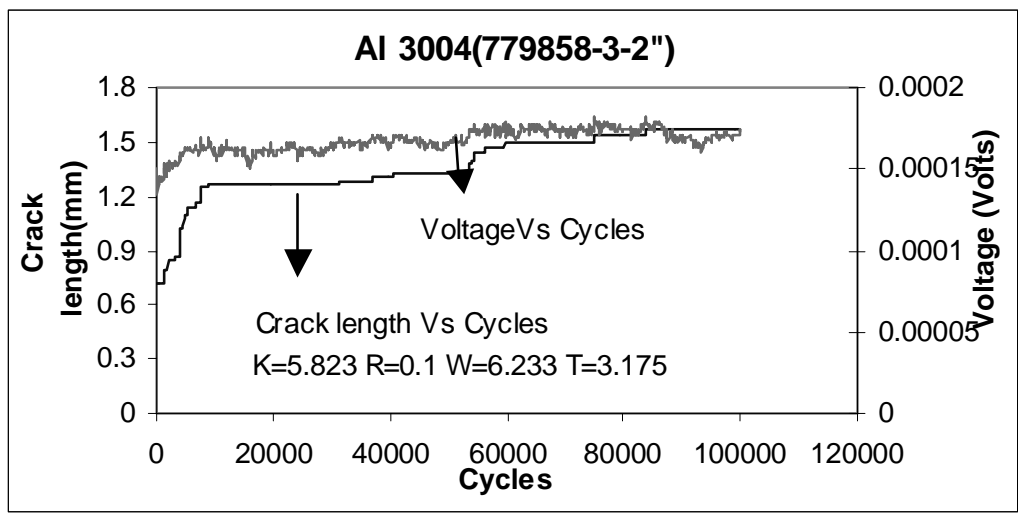

A7. Voltage, Crack length Vs No of cycles for Al 3004 (779858-3-2”)

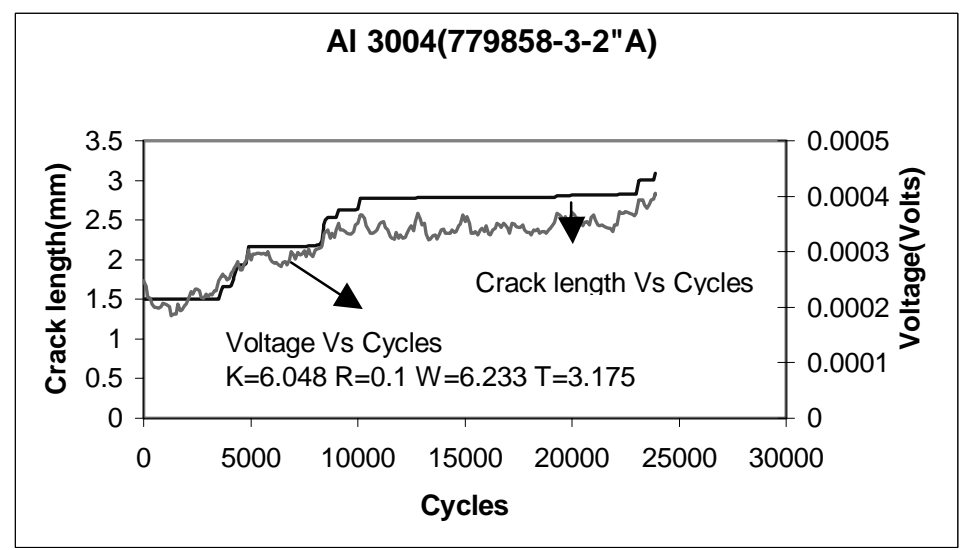

A8. Voltage, Crack length Vs No of cycles for Al 3004 (779858-3-2”A) 


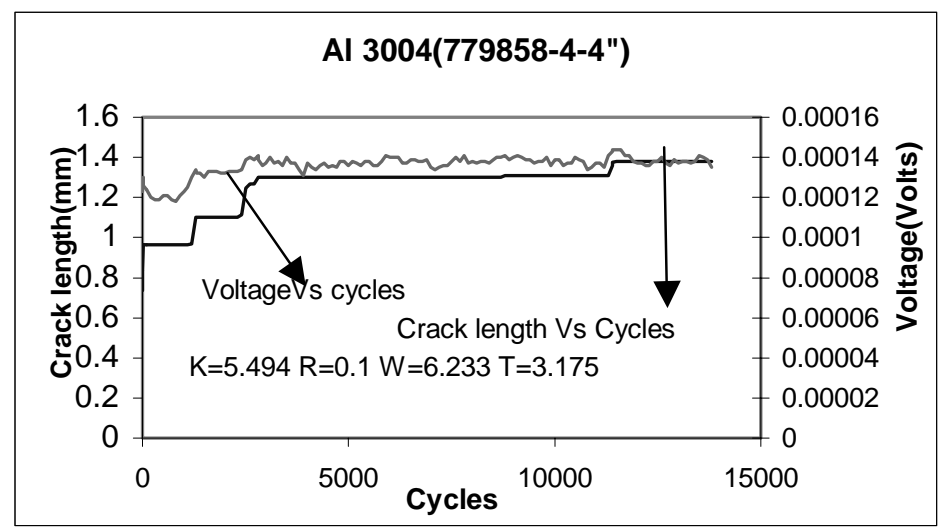

A9. Voltage, Crack length Vs No of cycles for Al 3004 (779858-4-4”)



A10. Voltage, Crack length Vs No of cycles for Al 3004 (779858-4-4"A) 


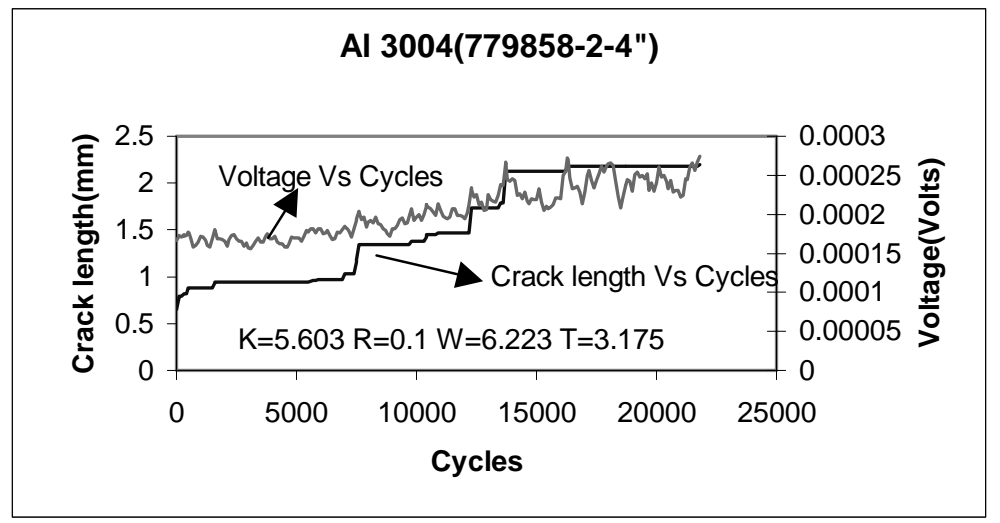

A11. Voltage, Crack length Vs No of cycles for Al 3004 (779858-2-4”)

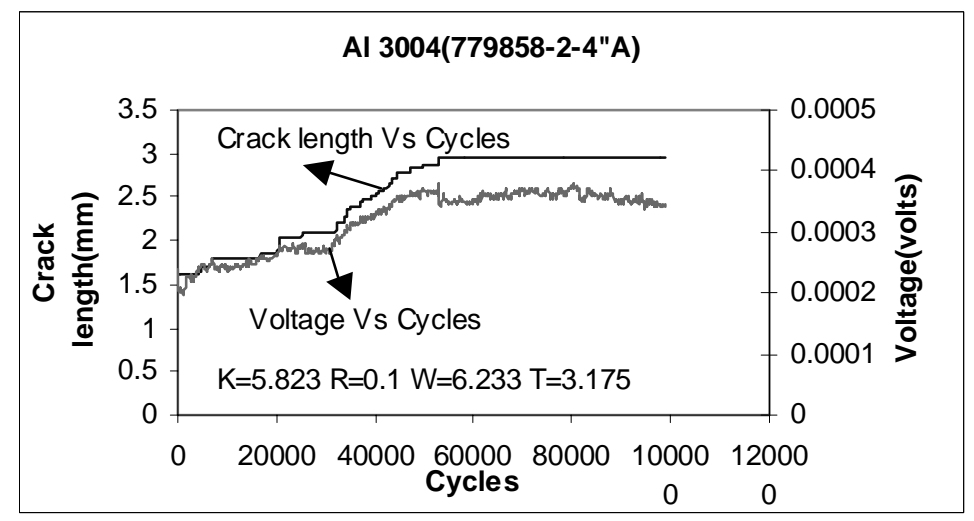

A12. Voltage, Crack length Vs No of cycles for Al 3004 (779858-2-4”A) 


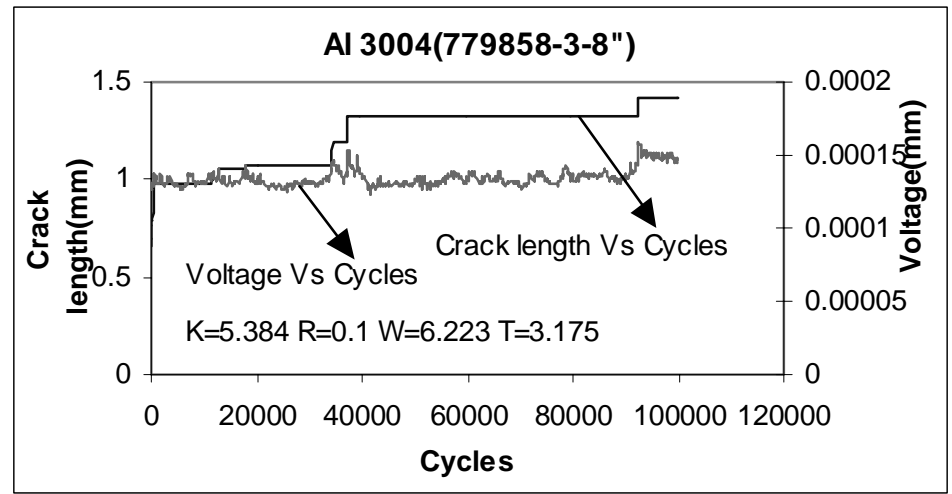

A13. Voltage, Crack length Vs No of cycles for Al 3004 (779858-3-8”)

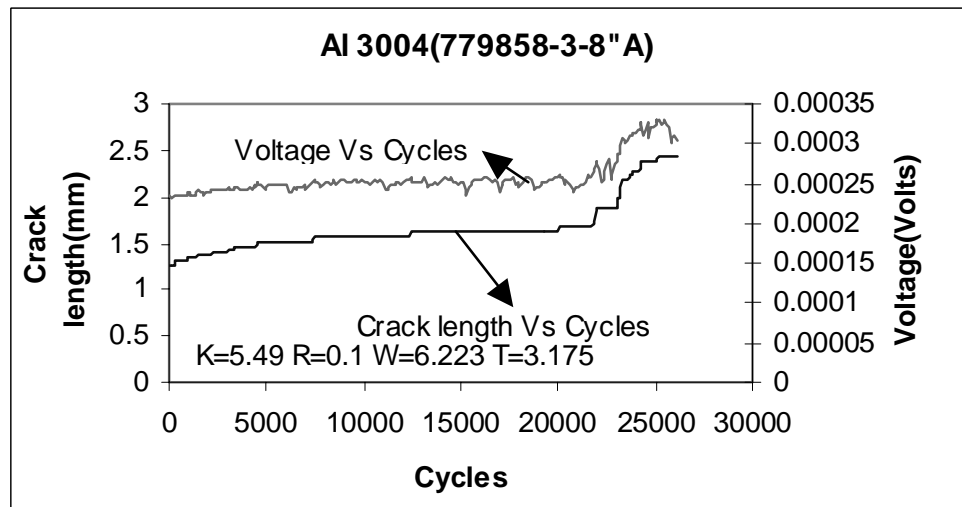

A 14. Voltage, Crack length Vs No of cycles for Al 3004 (779858-3-8”A) 
Precrack length for 2024 and 3004Alloys using Calipers:

For 2024 Alloys:

\begin{tabular}{|l|c|}
\hline SPECIMEN CODE & PRE CRACK LENGTH $(\mathrm{mm})$ \\
\hline $779857-2-1 "$ & 2.413 \\
\hline $779857-3-1 "$ & 2.311 \\
\hline $779857-4-2 "$ & 2.159 \\
\hline $779857-2-2 "$ & 2.235 \\
\hline $779857-2-4 "$ & 2.209 \\
\hline $779857-2-8 "$ & 2.032 \\
\hline $779857-3-8 "$ & 1.981 \\
\hline
\end{tabular}

For 3004 Alloys:

\begin{tabular}{|l|l|}
\hline SPECIMEN CODE & PRECRACK LENGTH (mm) \\
\hline $779858-4-2 "$ & 4.140 \\
\hline $779858-3-2 "$ & 3.098 \\
\hline $779858-4-4 "$ & 3.429 \\
\hline $779858-2-4 "$ & 3.352 \\
\hline $779858-3-8 "$ & 2.336 \\
\hline
\end{tabular}




\section{All. QUENCH CRACK CURVES:}

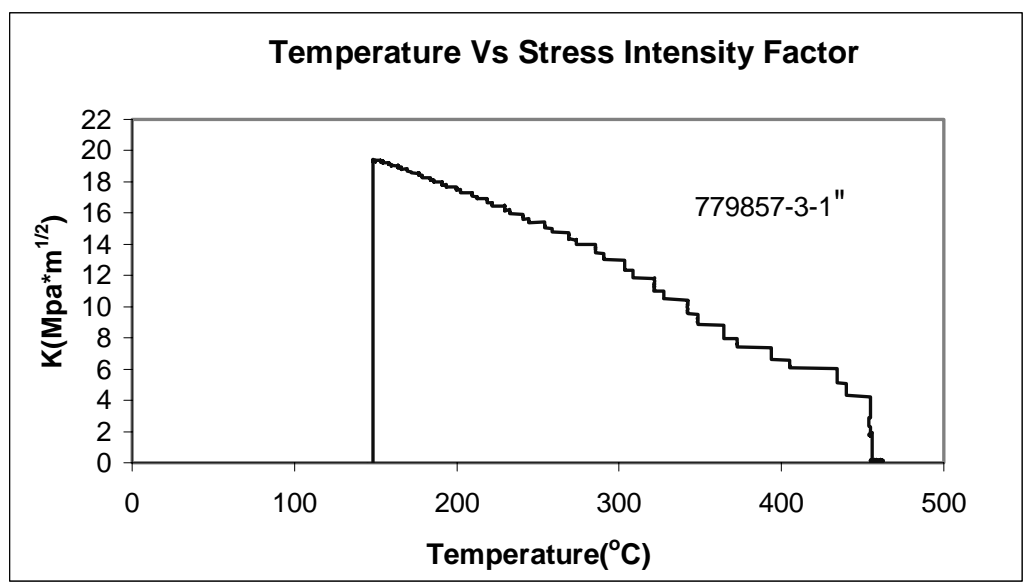

A15. Temperature Vs Stress Intensity Factor Al 2024(779857-3-1")

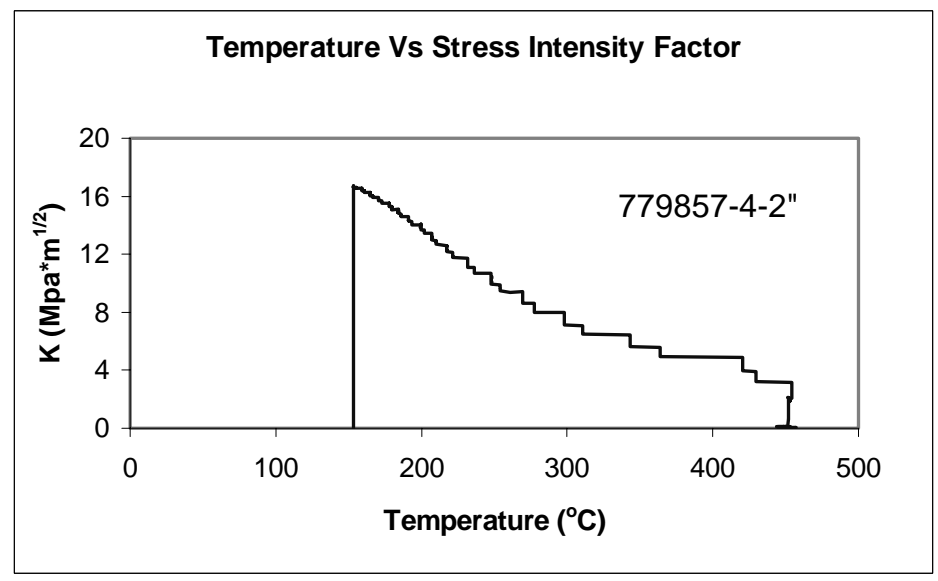

A16. Temperature Vs Stress Intensity Factor Al 2024(779857-4-2”) 


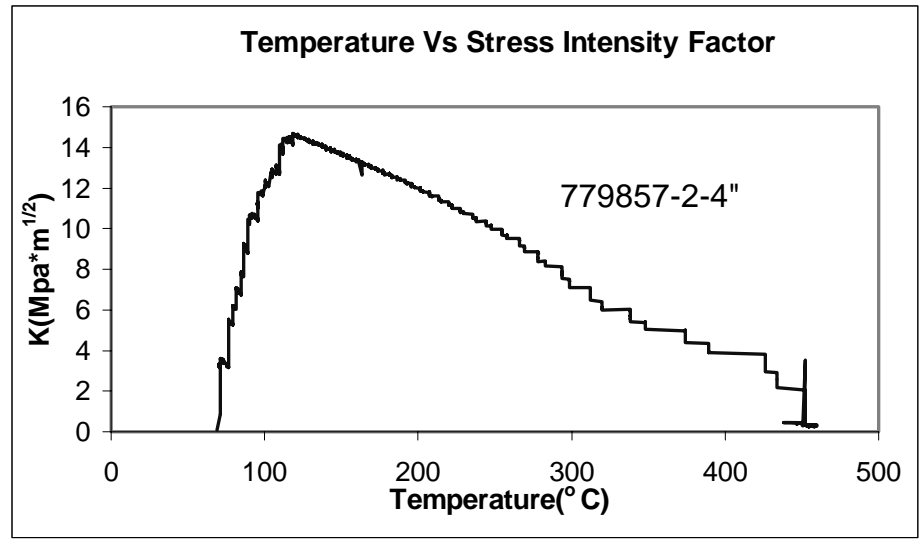

A17. Temperature Vs Stress Intensity Factor Al 2024(779857-2-4")

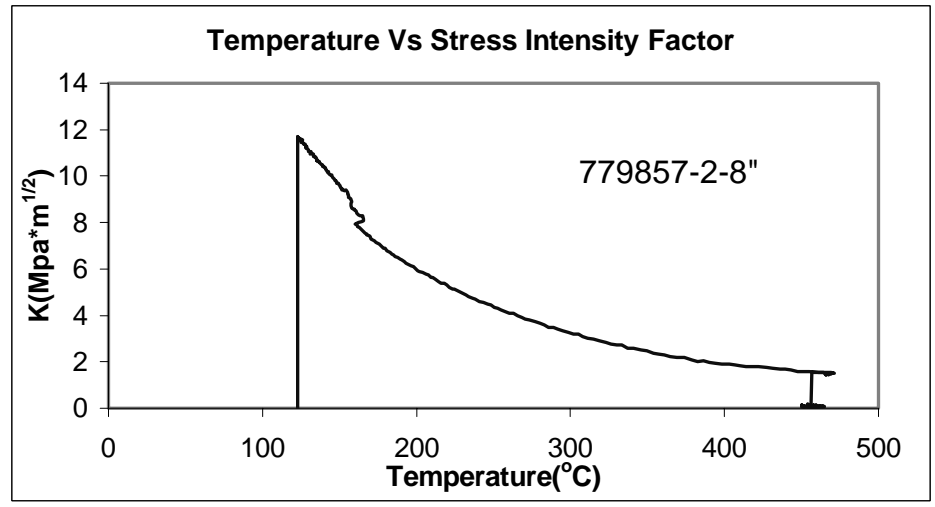

A18. Temperature Vs Stress Intensity Factor Al 2024(779857-2-8”) 


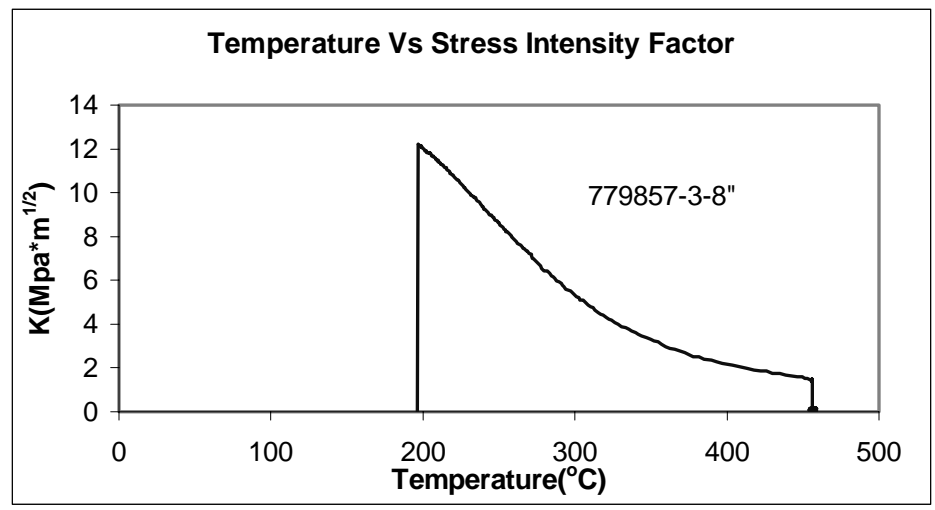

A19. Temperature Vs Stress Intensity Factor Al 2024(779857-3-8”)

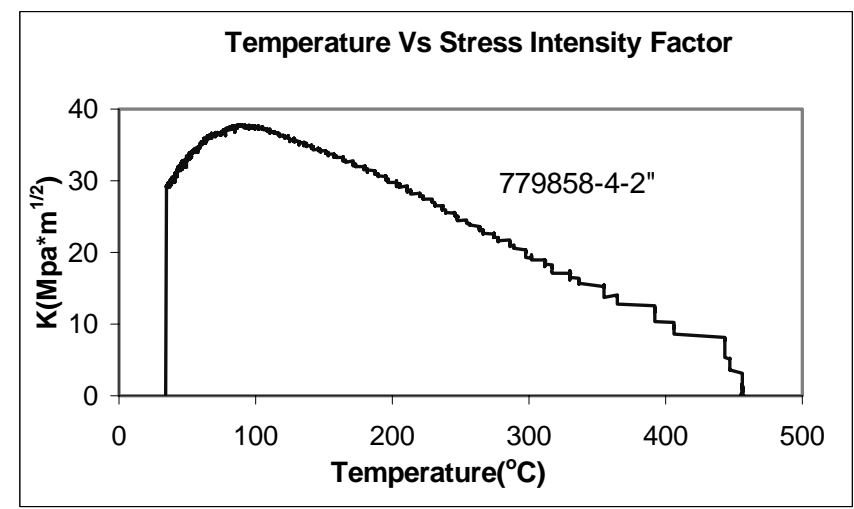

A20.Temperature Vs Stress Intensity Factor Al 3004(779858-4-2”) 


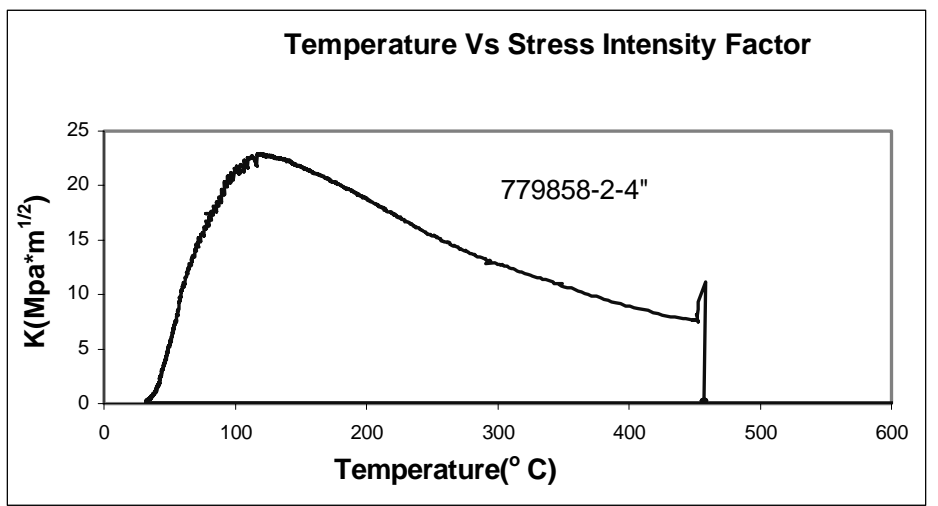

A 21. Temperature Vs Stress Intensity Factor Al 3004(779858-2-4”)

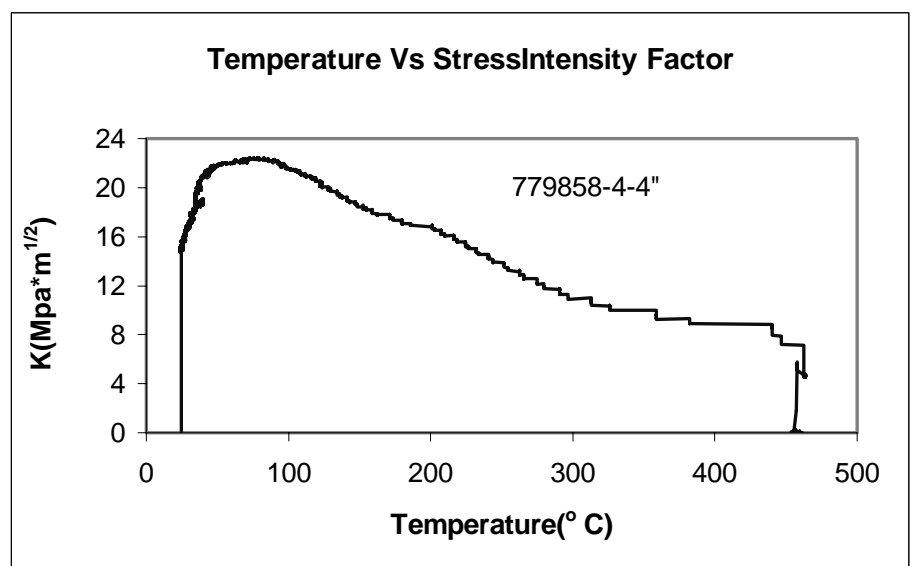

A22.Temperature Vs Stress Intensity Factor AI 3004(779858-4-4”) 


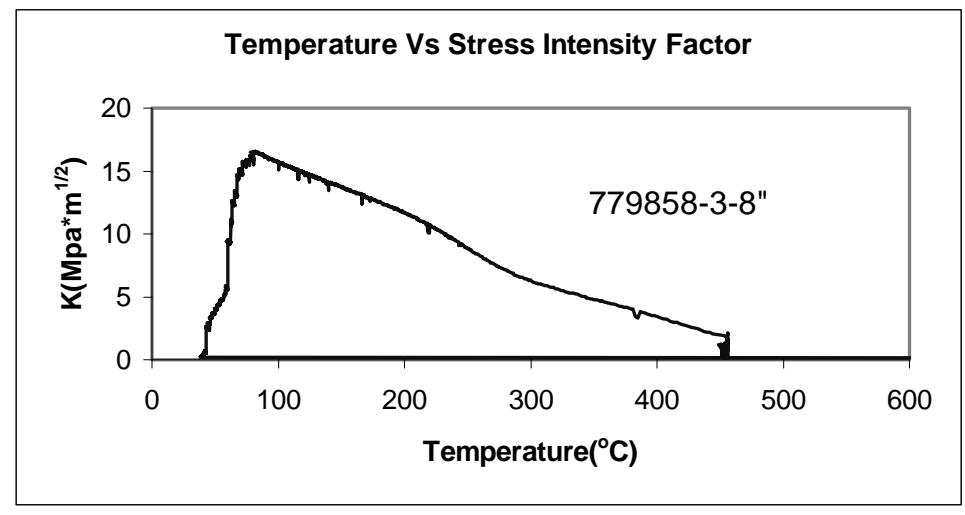

A23. Temperature Vs Stress intensity Factor Al 3004(779858-3-8”) 


\section{VITA}

Rohit Paramatmuni was born in India on September $7^{\text {th }} 1978$ He graduated with bachelors of engineering from University of Madras majoring in mechanical engineering in May 2000.During his undergraduate study he worked as an intern at BHEL(R\&D) from Dec 1999 to March 2000 working on the theoretical and dynamic behavior of a rotor dynamic test rig used for machine fault diagnosis studies. Currently he is on the verge of completion of his masters degree in mechanical engineering specializing in Solid mechanics and Materials from West Virginia University. 